\title{
An Ontological and Reasoning Approach to System of Systems
}

\section{Ludvig Knöös Franzén}





\title{
An Ontological and Reasoning Approach to System of Systems
}

\author{
Ludvig Knöös Franzén
}

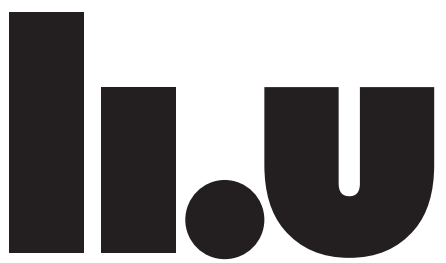

LINKÖPING UNIVERSITY

Division of Fluid and Mechatronic Systems

Department of Management and Engineering

Linköping University, SE-581 83 Linköping, Sweden 
(oc) EY-No This work is licensed under a Creative Commons AttributionNonCommercial 4.0 International License.

https://creativecommons.org/licenses/by-nc/4.0/

Copyright @ Ludvig Knöös Franzén, 2021

An Ontological and Reasoning Approach to System of Systems

ISBN 978-91-7929-635-3

ISSN 0280-7971

Cover: Ludvig Knöös Franzén, 2021

\section{Distributed by:}

Division of Fluid and Mechatronic Systems

Department of Management and Engineering

Linköping University

SE-581 83 Linköping, Sweden

Printed in Sweden by LiU-Tryck, Linköping 2021. 
To my Friends and Family

Gör man rätt från början blir det inga fel 



\section{Abstract}

System-of-Systems (SoS) are all around us and are becoming more common in today's highly interconnected world. Systems are connected with other systems and have strong dependencies with their operational environments. This leads to an increased level of complexity and risk during product development. A holistic view, and an SoS perspective, is consequently needed in order to develop an early understanding of the available design spaces for new system solutions. This thesis suggests a method that has been developed for this purpose, and to meet the demand for a more holistic product development. Overall, the method consists of two correlated approaches that show how a design space for SoS $\$$ can be generated and later processed with, for example, design space reductions. Search and Rescue (SAR) operations have been used as examples of typical SoSs throughout this work and in the development of the presented method. An architecture framework has been used to introduce a standardized and consistent way of understanding the relationships that exist between needs, capabilities and functions. This approach can consequently be used to generate a design space of functions to be performed to meet the overarching needs of an $\mathrm{SoS}$ The second approach has been based on ontology and description logic reasoning. Ontology has here been used to represent an SoS design space with, for example, available SAR assets and their relationships with the operational environment. An SoS representation in an ontology model introduces additional expressiveness and the design space processing capabilities needed for a holistic design process and product development. Based on these results, this thesis and its suggested method and approaches contribute to holistic product development from an SoS perspective. 


\section{Acknowledgements}

This work has been carried out at the Division of Fluid and Mechatronic Systems (Flumes) at Linköping University. The research has been performed under the System-of-Systems Trade Space Exploration (S2TEP) project funded by the National Aeronautics Research Programme (NFFP7) under the Swedish Agency for Innovation (VINNOVA), and Saab Aeronautics.

I would like to start by expressing my gratitude to my main supervisor, Professor Petter Krus, who has been both a source of inspiration and an excellent guide in my academic journey. I also dedicate my deepest gratitude to my co-supervisors Dr. Ingo Staack, Dr. Christopher Jouannet and Dr. Kristian Amadori. Thank you for your endless support, dedication and inspiration. I would additionally like to thank you all for the interesting and enjoyable discussions that we have had about most things in this universe.

I would like to particularly thank Rita Enquist for her great support in helping me navigate the ocean of administration at the university.

Special thanks go to all of my colleagues at Flumes. Thank you all for the many interesting discussions, activities and enjoyable coffee drinking sessions.

My gratitude also goes to my family and especially my parents and sister for unconditionally supporting me throughout all of my educational endeavours so far. You're the best! Finally, I would like to express my deepest gratitude to my wife Mathilda, who has supported me in every way since the day we first met. Thank you and our "little" dog Wille for enduring my endless repetitions about my everyday concerns. This thesis is dedicated to you.

Tack!

Linköping, May 2021

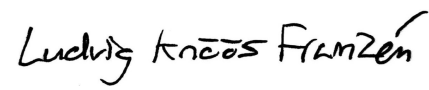

Ludvig Knöös Franzén 


\section{Abbreviations}

\begin{tabular}{|c|c|}
\hline $\mathrm{ABS}$ & Agent-Based Simulations \\
\hline ASDL & Aerospace Design Laboratory \\
\hline $\mathrm{BFO}$ & Basic Formal Ontology \\
\hline CONOPS & Concept of Operations \\
\hline $\mathrm{CS}$ & Constituent Systems \\
\hline DoDAF & $\begin{array}{l}\text { US Department of Defense Architecture Frame- } \\
\text { work }\end{array}$ \\
\hline DSM & Design Structure Matrix \\
\hline $\mathrm{F} / \mathrm{M}$ tree & Function/Means tree \\
\hline FEAF & Federal Enterprise Architecture Framework \\
\hline FLAR & Forward Looking Airborne Radar \\
\hline IAMSAR & $\begin{array}{l}\text { International Aeronautical and Maritime Search } \\
\text { and Rescue }\end{array}$ \\
\hline INCOSE & International Council On Systems Engineering \\
\hline IRMA & $\begin{array}{l}\text { Interactive Reconfigurable Matrix of Alterna- } \\
\text { tives }\end{array}$ \\
\hline JRCC & Joint Rescue Co-ordination Centre \\
\hline LKP & Last Known Position \\
\hline MBSE & Model Based Systems Engineering \\
\hline MODAF & $\begin{array}{l}\text { UK Ministry of Defence Architecture Frame- } \\
\text { work }\end{array}$ \\
\hline MoE & Measures of Effectiveness \\
\hline MTTD & Mean Time To Detection \\
\hline NAF & NATO Architecture Framework \\
\hline OBSE & Ontology-Based Systems Engineering \\
\hline OWL & Web Ontology Language \\
\hline OWL-DL & Web Ontology Language - Description Logics \\
\hline PDF & Probability Density Function \\
\hline QFD & Quality Function Deployment \\
\hline $\mathrm{RDF}$ & Resource Description Framework \\
\hline SAR & Search and Rescue \\
\hline SE & Systems Engineering \\
\hline
\end{tabular}


SMA Swedish Maritime Administration

SoS System-of-Systems

SoSE System-of-Systems Engineering

SS Sub-Systems

SysML Systems Modelling Language

TOGAF The Open Group Architectural Framework

UAF Unified Architecture Framework

UML Unified Modelling Language

UPDM Unified Profile for DoDAF and MODAF

XML Extensible Markup Language 


\section{Papers}

This compilation thesis is based on the following papers that consequently can be regarded as its foundation. The papers are chronologically appended and represent their original forms, apart from minor formatting changes. Throughout this thesis, the appended papers are referred to by their Roman numerals. The author of this thesis is the main author of all the appended papers and the co-authors have made supervisory contributions. Chapter 7 presents a short summary of the content for each appended paper.

[I] L. Knöös Franzén, I. Staack, C. Jouannet, and P. Krus. "An Ontological Approach to System of Systems Engineering in Product Development". In: Proceedings of the 10th Aerospace Technology Congress (FTF). Stockholm: Swedish Society of Aeronautics and Astronautics, 2019, pp. 35-44. DOI: 10.3384/ecp19162004.

[II] L. Knöös Franzén et al. "A System of Systems Approach for Search and Rescue Missions". In: Proceedings of the AIAA Scitech 2020 Forum. Orlando, Florida: American Institute of Aeronautics and Astronautics, 2020, pp. 1-16. DOI: 10.2514/6.2020-0455.

[III] L. Knöös Franzén et al. "A Breakdown of System of Systems Needs Using Architecture Frameworks, Ontologies and Description Logic Reasoning". In: Aerospace 8.4 (2021). ISSN: 2226-4310. DOI: 10 . $3390 /$ aerospace8040118. 


\section{Additional Publications}

The following publications have also been produced by the author of this thesis. However, these are not included as appended papers.

[IV] L. Franzén and E. Magnusson. "Weight Penalty Methods for Conceptual Aircraft Design". In: Master Thesis Report LIU-IEI-TEK-A-18/03188SE, 2018.

[V] K. Amadori, C. Jouannet, L. Knöös Franzén, and E. Magnusson. "Weight Estimation for Conceptual Design: Refurbishing and Tweaking of Older Methods". In: Proceedings of the AIAA Scitech 2019 Forum. San Diego, California: American Institute of Aeronautics and Astronautics, 2019, pp. 1-11. DOI: 10.2514/6.2019-0257

[VI] L. Knöös Franzén. "A System of Systems View in Aerospace Product Development". In: Book of abstracts for the 3rd ECATS Conference, Making Aviation Environmentally Sustainable. Vol. 1. Gothenburg, Sweden (Online): ECATS and the Swedish Aerospace Research Center (SARC), 2020, pp. 245-249. ISBN: 978-1-910029-58-9.

[VII] L. Knöös Franzén. "System of Systems: Trade Space Exploration: with Ontology and Description Logic Reasoning". In: Proceedings of the 12th International Joint Conference on Knowledge Discovery, Knowledge Engineering and Knowledge Management. Online Streaming: IC3K, 2020, pp. 1-7. 


\section{Contents}

\begin{tabular}{ll|l}
1 & Introduction & 1
\end{tabular}

1.1 Background . . . . . . . . . . . . . . . . . . 1

1.1.1 Previous Research at Linköping University . . . . . . . 3

1.2 Aim and Research Questions . . . . . . . . . . . . . . 5

1.3 Delimitations . . . . . . . . . . . . . . . . . 5

1.4 Contribution . . . . . . . . . . . . . . . . . . . . . . 6

1.5 Methodology . . . . . . . . . . . . . . . . . . . . . 6

1.6 Thesis Outline . . . . . . . . . . . . . . . . . . . . 8

\begin{tabular}{|lll}
\hline & Theoretical Background & 9
\end{tabular}

2.1 System of Systems . . . . . . . . . . . . . . . . . . . . . . . . . . 9

2.2 System of Systems Engineering . . . . . . . . . . . . . . . . 11

$2.2 .1 \quad$ Model Based Systems Engineering . . . . . . . . . . . . 12

2.2 .2 Architecture Frameworks . . . . . . . . . . . . . 13

2.2 .3 System of Systems Modelling and Simulation . . . . . . 14

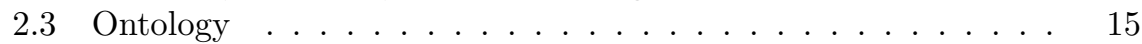

2.3 .1 Top-Level and Meta Ontologies . . . . . . . . . . . . . . 17

2.3.2 Ontology-Based Systems Engineering. . . . . . . . . . . 18

2.4 Product and Engineering System Development . . . . . . . . . 19

2.4 .1 Design Space Explorations . . . . . . . . . . . . . . 19

2.4 .2 Concept Generation Approaches . . . . . . . . . . . . . 21

\begin{tabular}{|lll}
3 & System of Systems and Ontology in Product Development & 23
\end{tabular}

3.1 Search and Rescue as a Case Study . . . . . . . . . . . . 24

3.2 Architecture Framework Approach . . . . . . . . . . . . . . . 25

\begin{tabular}{lll}
\hline 3.2 .1 & Breakdown of System of Systems Needs Using the Unified & \\
& Architecture Framework . . . . . . . . . . . . . 26
\end{tabular}

3.2.2 Outcome and Design Space . . . . . . . . . . . . . . . . . 28

3.3 Ontology and Reasoning Approach . . . . . . . . . . . . . . . . 28

3.3.1 Building an Ontology for an SoS Design Space . . . . . 29

3.3 .2 Reasoning and Design Space Processing . . . . . . . . . 34

$3.3 .3 \quad$ Ontology Approach Outcome and Opportunities . . . . 36 


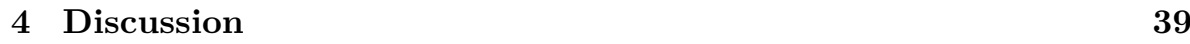

$\begin{array}{|ll|}5 & \text { Conclusions }\end{array} 43$

6 Outlook and Future Work 45

\begin{tabular}{|ll|}
\hline 7 & Review of Papers
\end{tabular}

\begin{tabular}{ll}
\hline Bibliography & 49
\end{tabular}

\section{Appended Papers}

I An Ontological Approach to System-of-Systems Engineering $\begin{array}{ll}\text { in Product Development } & 57\end{array}$

II A System of Systems Approach for Search and Rescue Missions 83

III A Breakdown of System of Systems Needs Using Architecture Frameworks, Ontologies and Description Logic Reasoning 


\section{1 \\ Introduction}

System-of-Systems (SoS) has become a constantly growing field of research in Systems Engineering (SE)] and product development [1]. Systems are becoming more connected with other systems and their operational environments. The increased number of interconnections lead to new levels of complexities that need to be understood and managed in the early development of new system solutions. To further complicate things, the operational environment is constantly changing and thereby introducing a higher level of risk and uncertainty during development. This is especially true for e.g. aerospace systems, which often have inherently long development times, spanning several years or even decades. Aerospace systems also have long expected lifespans, which makes them susceptible to changes in initially specified requirements. Consequently, solutions with long development time might be rendered obsolete before they are even produced due to changes in the outside world. Therefore, a holistic view of the development process is needed to ensure resilience and to explore the influence of possible future changes in the operational environment and outside world. The focus is consequently shifting from only fulfilling fixed sets of requirements to being able to deliver capabilities over time and throughout changing circumstances. However, a holistic view implies that more aspects than just single system solutions must be considered during the early phases of development. As a response, this thesis shows how an SoS perspective with ontology can be used to approach complex product development in a holistic way.

\subsection{Background}

The term "system" can be found in almost any area of research. A general definition of a system is that it is an arrangement of parts or elements that together produce results, behaviour or meaning not obtainable by the individual elements alone [2]. An aircraft is in this sense a system that consists of 
different elements or parts that together make the system airworthy. The elements of a system can themselves be systems and are called sub-systems. It is tempting to say that an aircraft is a complex system composed of systems and sub-systems. However, an aircraft is not an SoS. What is then the difference between a complex system and an SoS? The International Council On Systems Engineering (INCOSE) defines an SoS as an interoperating collection of Constituent Systems (CS) that usually produce results that the individual systems cannot achieve alone [3. A CS can be part of more than one SoS and can also be composed of several sub-systems that in turn can include their own sub-systems and system elements, or parts. An illustration of a hierarchy for SoSs, CS sub-systems and system elements can be seen in Figure 1.1 .

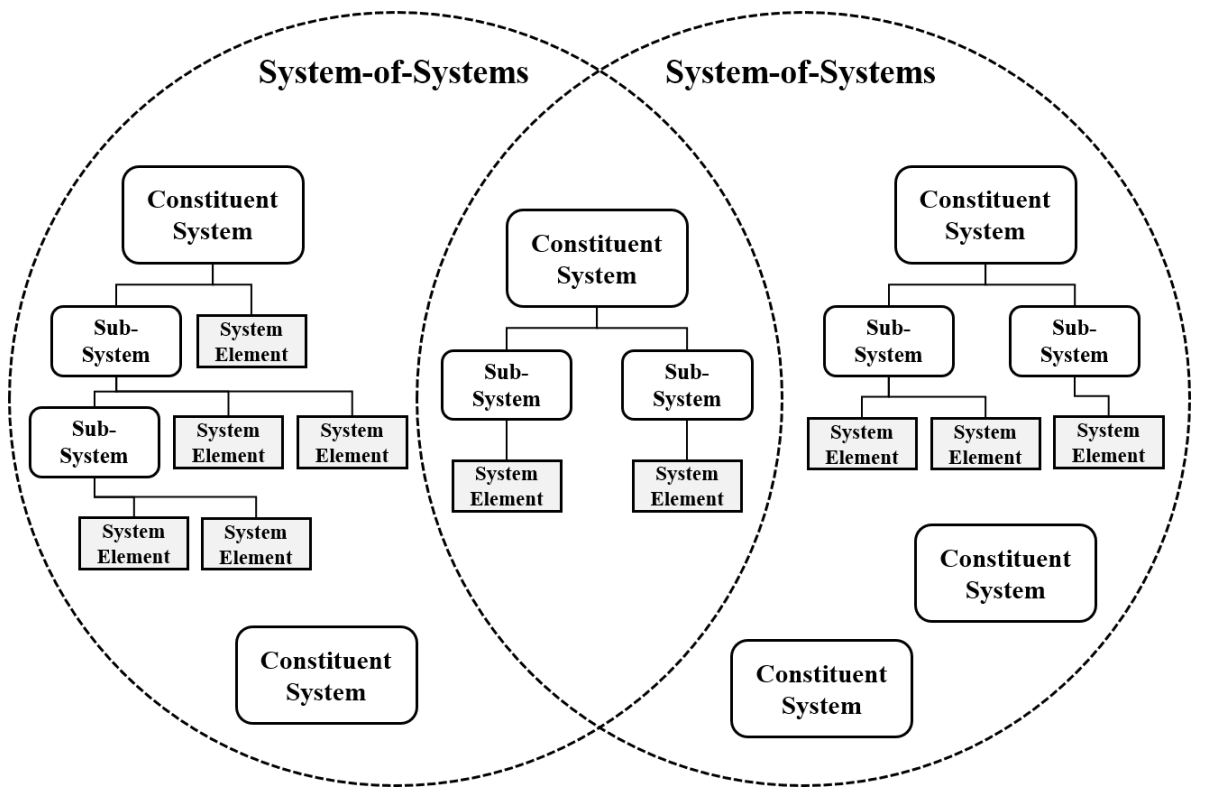

Figure 1.1 An example of a hierarchy comprising System-of-Systems (SoS). Constituent Systems (CS), sub-systems and their corresponding system elements.

The difference between a system and an SoS can be hard to tell from their quite similar definitions. However, an SoS can be distinguished from a system based on five different characteristic properties introduced by Mark W. Maier [4]. These describe how a system can be better understood as an SoS if it has the following characteristic properties:

- Operational independence

- Managerial independence

- Geographical distribution 
- Emergent behaviour

- Evolutionary development

Operational independence specifies that each of the CS should be able to operate on their own and still be able to fulfil their individual purposes if disconnected from the other CS Similarly, managerial independence requires that the CS can be developed by different manufacturers and that they can be managed and maintained by different organizations. A geographical distribution of the CS means that the distance between them is typically large and that the main form of interactions between them are information exchanges rather than physical connections. Emergent behaviours can appear once CS are interacting. Consequently, the emergent behaviour property describes the ability of the CS to produce unique behaviours through collaboration. These can, for example, be capabilities that the individual constituents cannot achieve on their own, but can also correspond to unwanted behaviours that may arise through system interactions. Evolutionary development implies that an $[\mathrm{SoS}$ is under constant evolution and that its composition can vary. Consequently, new CS can be added and old ones removed over time. The definition listed above is used throughout this thesis to distinguish a complex system from an SoS. Based on the definitions above, SoSs in the aerospace sector are, for example, entire air defence systems, the air transport system, aircraft carriers with assigned aircraft squadrons, drone swarms, and Search and Rescue (SAR) systems, to name a few.

The development of systems and SoSs can be referred to as Systems Engineering (SE) and System-of-Systems Engineering (SoSE), The field of Systems

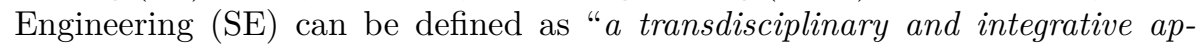
proach to enable the successful realization, use, and retirement of engineered systems, using systems principles and concepts, and scientific, technological, and management methods" 2]. SE consequently involves the engineering design of systems but also the identification of customer needs and the influence of the operational environments and other external factors that must be accounted for during development [5]. SoSE focuses on the integration of CS to obtain capabilities that the singular systems cannot achieve on their own [6]. SoSE thereby facilitates the development of interoperable system solutions that can deliver capabilities over a long-term perspective. Having an SoS perspective and a capability-based focus is becoming a necessity in today's complex product development, especially in the aerospace sector.

\subsubsection{Previous Research at Linköping University}

Previous research related to this thesis has proposed a holistic approach for product development in the context of SoSE and aerospace 1]. This approach assumes that a holistic design process for SoS can be divided into five main levels of interest. The goal of the process is to create an early understanding 
of an SoS under development and how its design can be holistically explored. The five levels are illustrated in Figure 1.2

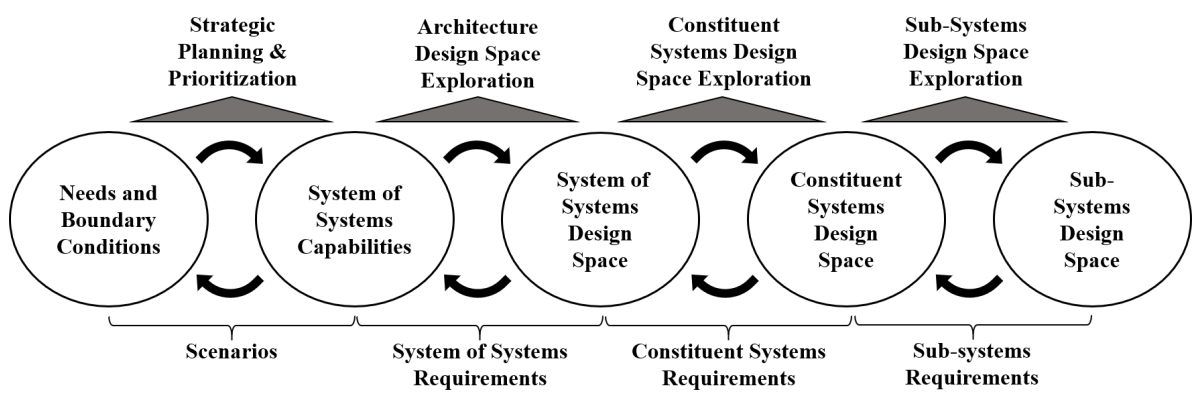

Figure 1.2 An overview of the holistic design process for SoS. Adapted from [1].

Starting from the left, the Needs and Boundary Conditions level in Figure 1.2 focuses on analysing the overall needs of the SoS which typically are those of the involved customers or stakeholders. The boundary conditions of an SoS have an influence on the needs and can be aspects such as politics, economy, technology and more. Time frames are also an important aspect that may affect the needs as boundary conditions are constantly changing. The next level describes the SoS capabilities required to meet the needs. The capabilities are determined by analysing different scenarios to understand the influence of changing boundary conditions. The capabilities most resilient to changes can consequently be identified by exploring the design space. The System of Systems Design Space level is used to investigate how the desired capabilities can be achieved. This is done by performing architecture design space explorations to find all valid SoS solutions. This consequently generates an SoS design space where each valid SoS solution is represented. Each SoS is composed of CS that together achieves the capabilities. The Constituent System Design Space level focuses on the design of the individual systems of the SoS Here, traditional product development processes are used to design the systems based on derived requirements. Finally, the Sub-System Design Space level is used to explore how the sub-systems can be designed. The process just described is recurrent and has no specific starting point. This means that an analysis could start at the sub-system level and involve investigations into whether additional capabilities can be achieved by incorporating a new technology, for example.

The holistic SoS design process is a central part of this thesis and the related method for approaching the problem outlined in the introduction. 


\subsection{Aim and Research Questions}

The overall purpose of this thesis is to produce methods and approaches for product development from an SoS perspective. Accordingly, the thesis aims to provide realizations of parts of the holistic SoS design process in Figure 1.2 On a more specific level, this thesis intends to answer the following research questions derived from the problem outlined in the previous sections:

- RQ1: How can the needs of a system-of-systems be broken down into required capabilities and subsequently functions to be performed by constituent systems in a standardized and consistent way?

- RQ2: How can a design space for system-of-systems be represented in a flexible manner that allows explorations?

- RQ3: In what way can a design space for system-of-systems be reduced and explored in an efficient and traceable way?

\subsection{Delimitations}

The highly combinatoric nature of SoSs makes the development of methods for approaching it hard without introducing some delimitations. This thesis mainly focuses on design processes from an SoS perspective and how an SoS design space representation can be created and processed. Consequently, other aspects of SoS $\$$ are therefore not covered in detail. Additional delimitations considered in this thesis are listed below:

- No evaluation of particular solutions: The interaction between CS can create emergent SoS capabilities. Different SoS solutions can therefore result in similar available capabilities and performances. This thesis focuses on the methods and approaches that can be used to create an SoS solution. The performance of particular SoS solutions is therefore not measured or evaluated.

- Only Search and Rescue as application area: There are many examples of SoS application areas that can be used as case studies to test produced methods. However, in order to keep the generated design spaces at a manageable level, only Search and Rescue (SAR) will be used as an application area.

- Low fidelity levels: Performed case studies are kept at a basic level with generally low fidelity to illustrate the utilization of produced methods and approaches.

- No new definitions for SoSs: The thesis builds upon existing definitions of SoS $\$$ and will consequently not be used to provide new definitions for characterizing SoS or differentiate them from complex systems. 


\subsection{Contribution}

This thesis contributes a method for realizing parts of the holistic SoS design process illustrated in Figure 1.2. The thesis thereby also provides examples of how an SoS perspective can be used in aerospace product development. The performed work is kept at a general level so that the representation of any SoS is facilitated. Consequently, the presented method is applicable in any product development and not just from an aerospace SoS perspective. It can therefore be used in the early design of CS and sub-systems as well.

From an industrial perspective, this thesis suggests how the presented method and its corresponding approaches can be used to process different design spaces in the early stages of product development. Additionally, the outcome can be used in traditional product development approaches for conceptual design to cover even more aspects. All the above-mentioned, together with a theoretical review of related areas and methods, contributes to the overall understanding and knowledge of SoS perspectives in engineering.

On a more specific level, this thesis shows how ontology and description logic reasoning can be used in an SoSE perspective and to represent as well as process a design space. The thesis also shows how an architecture framework can support product development and be used to obtain the functions to be performed by an SoS to meet overarching needs.

\subsection{Methodology}

The scientific methodology of this thesis is largely built upon hypotheticodeductive practices [7]. The formulation of hypotheses is done based on theories formed from literature studies. The hypotheses are then tested using experiments designed to challenge the assumptions. If the obtained results support the theories and prove the hypotheses right, they consequently form new methods and models to mimic reality. If proven to be wrong, new hypotheses can be formed based on the acquired knowledge from the performed experiments. Needless to say, the principles of the hypothetico-deductive process are highly iterative. This is illustrated in Figure 1.3

On a more technical level, the formulation of methods and approaches in the performed work has been based on the outcome of a literature review. The theoretical background has here been investigated to find similar initiatives, existing methods, procedures and tools from areas such as SE SoSE and more. As mentioned in chapter 1.1.1 the holistic SoS design process and its five levels of interest have been a central part of the approaches described in this thesis. In their article, Staack et al. also suggest different key enablers for holistic design engineering [1]. These key enablers have partly been used to narrow down the initial scope of the performed literature study as well. The results from reviewing the theoretical background have subsequently been used to formulate hypotheses and theories that have been believed to answer the posed research 


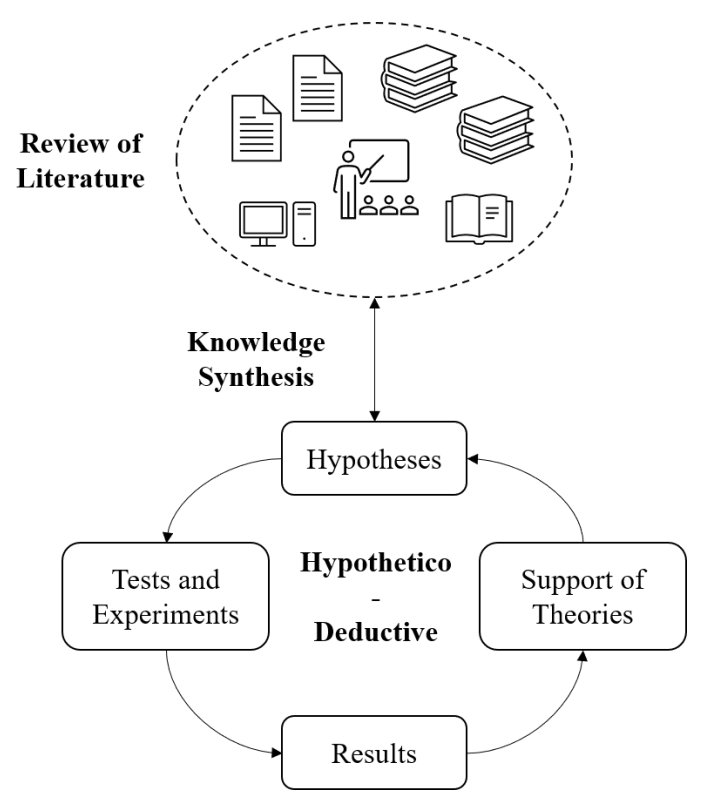

Figure 1.3 An illustration of the iterative process of acquiring knowledge to form and test hypotheses.

questions and the aim of the thesis. The hypotheses have thereafter been used to form a method with related approaches that each have contributed to the three research papers on which this thesis is built, namely papers [I, II, III]. Each of these approaches have been obtained by synthesising the knowledge from the literature review and utilizing the iterative process shown in Figure 1.3 The corresponding hypotheses have then been tested through the case studies of the appended papers in order to show their utility and to either update or confirm their hypotheses. Finally, the knowledge gained from each paper has been used to provide answers to the research questions of this thesis. Figure 1.4 shows an illustration of the overall methodology and workflow that has been used to perform this work.

As Figure 1.4 shows, ontology and architecture frameworks have been the main focus of the appended papers and the means of approaching the aim and research questions. 


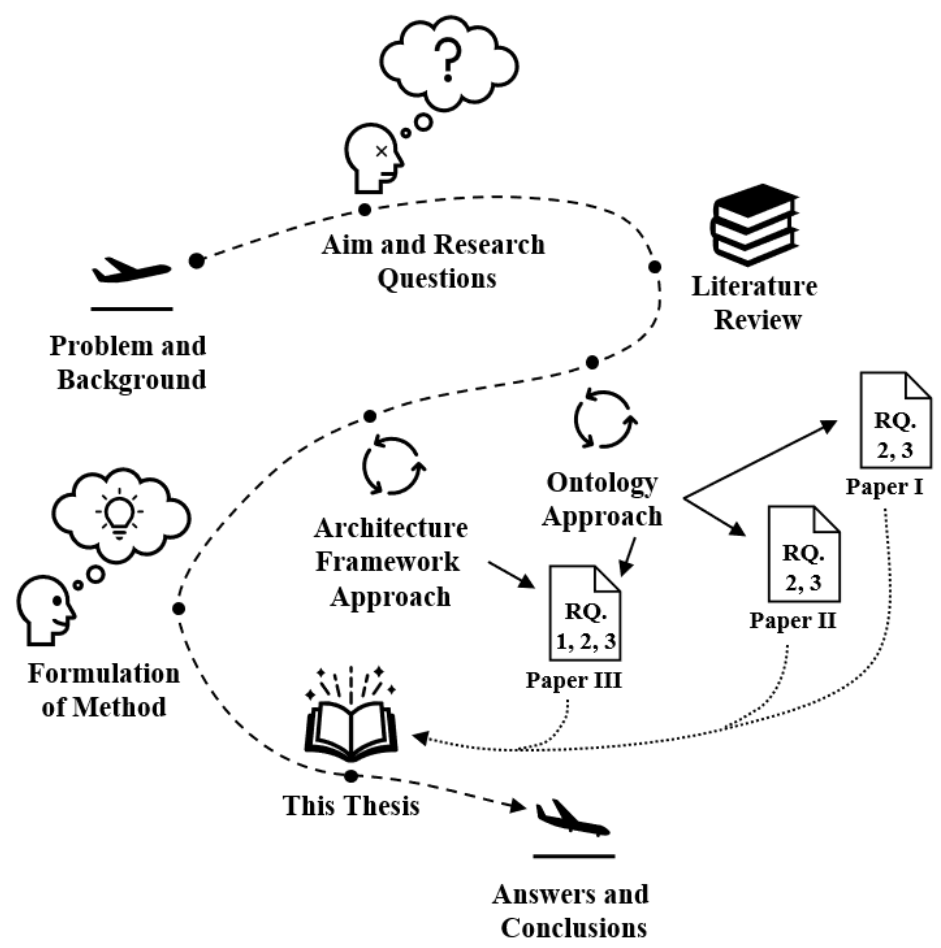

Figure 1.4 An illustration of the methodology that has been used to traverse the different steps leading to this thesis. The figure also shows where the different research questions $(R Q)$ have been addressed.

\subsection{Thesis Outline}

This thesis is structured in the following way: Chapter 2 provides a theoretical background and introduction to the different fields related to the presented research. Chapter 3 introduces the method and the corresponding architecture framework and ontology approaches that have been used to provide answers to the research questions and the aim of the thesis. The method, approaches and corresponding results are then discussed in chapter 4 and the overall content of the thesis is also discussed here. Chapter 5 concludes the thesis by answering the research questions and highlighting the most important conclusions. Brief thoughts about future work are presented in chapter 6. Finally, chapter 7 provides a short summary of the appended papers, which are found directly after chapter 7 


\section{2 \\ Theoretical Background}

The focus of this thesis is on product development from a holistic system-ofsystems (SoS) perspective, and there are many ways of approaching the problem outlined in the introduction. This chapter therefore provides both theory and background on the most closely related fields connected to this thesis and their corresponding methods and approaches. Similar research initiatives are also highlighted in this chapter.

\subsection{System of Systems}

The introductory chapter briefly touched upon definitions of systems and an $\mathrm{SoS}$, SoSs are similar to singular systems in many ways, and there are even those who believe that it can be misleading to treat them differently [8]. Still, others suggest that it can be valuable to recognize them as different to facilitate understanding [4]. There are various ways of distinguishing a system from an SoS, such as the "ABCDE-model" proposed in [9]. A widely used definition is Maier's five characteristic properties which were mentioned previously in chapter 1.1. Maier's definition is used to distinguish a system from an SoS throughout this thesis. Also, an $\mathrm{SoS}$ tends to have more differences compared to a system, as explained in [10]. These are listed below in Table 2.1. 
Table 2.1 The differences that systems tend to have compared with systems of systems [SoS). Adapted from [10].

\begin{tabular}{|l|l|}
\hline \multicolumn{1}{|c|}{ System } & \multicolumn{1}{c|}{ System of systems } \\
\hline A clear set of stakeholders & $\begin{array}{l}\text { Multiple levels of stakeholders that } \\
\text { may have mixed and competing in- } \\
\text { terests }\end{array}$ \\
\hline $\begin{array}{l}\text { Objectives and purposes are clearly } \\
\text { defined }\end{array}$ & $\begin{array}{l}\text { Multiple objectives and purposes } \\
\text { that can contradict each other }\end{array}$ \\
\hline $\begin{array}{l}\text { Explicit management structure and } \\
\text { accountabilities }\end{array}$ & $\begin{array}{l}\text { No clear accountability, and the } \\
\text { management structures can be dif- } \\
\text { ferent }\end{array}$ \\
\hline $\begin{array}{l}\text { The operational priorities are clear, } \\
\text { and priorities can also be resolved }\end{array}$ & $\begin{array}{l}\text { Multiple operational priorities that } \\
\text { can sometimes be different. No clear } \\
\text { routes for resolving priorities }\end{array}$ \\
\hline $\begin{array}{l}\text { The systems' ownership is clear, and } \\
\text { resources can be moved between ele- } \\
\text { ments }\end{array}$ & $\begin{array}{l}\text { Can include multiple owners that } \\
\text { make their own resourcing decisions }\end{array}$ \\
\hline Single life cycle & Multiple asynchronous life cycles \\
\hline
\end{tabular}

SoS $\$$ can also be categorized into different types, depending on their degree of centralized control [1]. The different categorizations are:

- Directed system of systems

- Acknowledged system of systems

- Collaborative system of systems

- Virtual system of systems

The directed category involves SoS s that have a high degree of centralized control. A directed SoS is typically both built and managed with the goal of fulfilling specific purposes. The Constituent Systems (CS) still have an operational independence, but are subordinated to the overall purpose of the SoS An integrated air defence network is as an example of a directed SoS that is centrally managed to defend a certain region against enemy systems [11].

An acknowledged SoS has a lesser degree of centralized control than a directed one. In this sense, the CS have more freedom and retain their independent properties, such as ownership, objectives and development. However, they do have commonly recognized objectives for the SoS. The INCOSE Systems of Systems Primer gives an air traffic control system as an example of an acknowledged SoS where the individual CS have common goals and follow overall regulations and protocols 10 .

Collaborative SoS have CS that voluntarily choose to participate to meet the overall purposes of the SoS Unlike directed and acknowledged SoSs, a collaborative SoS has no centralized control or overall directing authority. Collaborative 
SoSs do however have commonly agreed upon central purposes and follow standards, regulations and working practices. An example of a collaborative SoS, also given by [10], is electrical grids where CS together produce electricity and distribute it to customers.

Finally, a virtual SoS type is typically an SoS with no centralized control, authority or even a commonly recognized purpose. They often experience emergent behaviours on a large scale due to the lack of management and the consequential self-organization of CS. The internet is an example of an SoS that would be classified as a virtual type [10].

Furthermore, an SoS does not necessarily have to be of a specific type throughout its entire life cycle [10]. This depends on its current operating modes and the way it is viewed.

\subsection{System of Systems Engineering}

Unlike a system, an SoS is rarely developed from scratch [12]. As previously mentioned, the life cycles of the CS are often asynchronous, and SoS $\$$ are consequently rather formed over time as systems interoperate and collaborate to achieve new capabilities. SoSE can be seen as SE at an SoS level. SoSE involves the planning, analysis, organization and integration of CS to obtain capabilities not attainable by the individual systems alone [13, 14]. Compared with SE, SoSE involves a set of similar but different processes [14]. SE can also be distinguished from SoSE based on the differences displayed in Table 2.2

Table 2.2 A comparison between different attributes for SE and SoSE Adapted from [15].

\begin{tabular}{|l|l|l|}
\hline Property & Systems engineering & $\begin{array}{l}\text { System of systems } \\
\text { engineering }\end{array}$ \\
\hline Scope & A single complex system & $\begin{array}{l}\text { Multiple complex systems } \\
\text { that are integrated }\end{array}$ \\
\hline Objective & $\begin{array}{l}\text { Optimization against fixed } \\
\text { sets of requirements }\end{array}$ & $\begin{array}{l}\text { Satisfying and sustaining } \\
\text { capabilities to meet stake- } \\
\text { holder needs over time }\end{array}$ \\
\hline Boundaries & $\begin{array}{l}\text { Static and persistent } \\
\text { throughout the system's life } \\
\text { cycle }\end{array}$ & $\begin{array}{l}\text { Dynamic and changing over } \\
\text { time }\end{array}$ \\
\hline Problem & Defined & Emergent \\
\hline Structure & Hierarchy & Network \\
\hline Goals & Unitary & Pluralistic and aggregated \\
\hline Approach & Process & $\begin{array}{l}\text { Conthodology } \\
\text { constituent system life cy- } \\
\text { cles }\end{array}$ \\
\hline Timeframe & Single system life cycle \\
\hline
\end{tabular}


Capability engineering is a field which is similar to SoSE in many ways. It focuses on the identification, evaluation and integration of capabilities to ensure that they are properly designed and sustained from an interoperability perspective [16]. Capability engineering also extends SE principles to an SoS perspective. It is explained in [17 that capability engineering starts with the assessment of desired capabilities, followed by the identification of resources and viable options for achieving them. The options for achieving desired capabilities can then be assessed and selected. However, ensuring that capabilities can be met is near impossible through prototype testing in SoS The reason for this is that the complexity and overall large scale with multiple CS introduce both economic and physical barriers [18]. Consequently, modelling and simulation for complex systems and SoS becomes a valuable alternative in early design compared to prototype testing.

\subsubsection{Model Based Systems Engineering}

Model Based Systems Engineering (MBSE) is, as the name implies, systems engineering with a special focus on modelling aspects 3 . MBSE is used to increase the understanding of systems and their architectures, both during the development of new systems and in the deployment of existing ones [5]. MBSE has been used to model SoSs and to support the translations between capabilities and requirements, as shown in [19] and 20] for example. Different modelling languages are commonly used in MBSE to describe systems, their functionality, architecture and other properties. Two of these languages are the Unified Modelling Language (UML) and the Systems Modelling Language (SysML) both of which have been used to model and describe important aspects of SoS $17,19,21$. These aspects include things such as the architecture and information exchange between $\mathrm{CS}$, as well as their resulting emergent behaviours in the overall SoS

Understanding emergent behaviours is an important aspect in the development of complex systems and SoS s. The emergent behaviours of an SoS can be both wanted and unwanted [22]. The authors of 22 give bee colonies as an example of wanted emergent behaviours. Similarly, market crashes are given as an example of unwanted behaviours. Early development includes the identification of possible emergent behaviours so that they can be either facilitated or eliminated. Unique capabilities achieved through interoperation and collaboration between CS are examples of wanted emergent behaviours in SoSs where the sum is greater than the parts. MBSE is a means by which to identify these different behaviours early in the development process, and to facilitate the emergence of wanted behaviours and capabilities. In a similar way, unwanted behaviours can be avoided by analysing SoS architectures and the interoperation between CS with MBSE. 


\subsubsection{Architecture Frameworks}

The architecture of systems and SoS is an important aspect in MBSE, as previously mentioned. The Systems Engineering Guide for Systems of Systems describes how the architecture of an SoS defines the way the CS work together to meet user needs 14]. Here, it is also explained that an SoS architecture includes the Concept of Operations (CONOPS), which describes how CS can be employed. SoS architectures also include descriptions of the CS and their functions, as well as their external and internal dependencies and relationships. Finally, the communication and data flow, as well as the end-to-end functionality of the SoS can be described through an architecture.

Architecture frameworks have been developed for the purpose of describing the architectures of complex systems and SoSs. Architecture frameworks are also designed to capture the viewpoints of different stakeholders connected to an $\mathrm{SoS}$ 23. These different viewpoints can for example be operational, service, strategic, security and overall system aspects. Architecture frameworks that have been used to model SoSp in an MBSEffocused approach include the US Department of Defense Architecture Framework (DoDAF) the UK Ministry of Defence Architecture Framework (MODAF) and the NATO Architecture Framework (NAF) [20]. There are also other examples of architecture frameworks in $[\mathrm{SE}]$ and $[\mathrm{SoSE}]$ such as the Federal Enterprise Architecture Framework (FEAF), The Open Group Architectural Framework (TOGAF) and the Zachman Framework 23]. The Unified Profile for DoDAF and MODAF (UPDM) is another framework that supports the development of system architectures. As the name implies, it unifies DoDAF and MODAF to provide a common model for them. UPDM has been further developed into what is known as the Unified Architecture Framework (UAF) 24.

\section{The Unified Architecture Framework}

The UAF is designed to consistently model SoS architectures using an MBSE approach [25. It is closely connected with UML and SysML and thereby allows for improved interoperability with other related tools and standards. The UAF supports analyses of system specifications, design and verifications from different stakeholder views. Consequently, it allows stakeholders to analyse specific areas of interest in a holistic way that facilitates the fulfilment of desired capabilities in the SoS 24. Like DoDAF and MODAF the UAF introduces a number of different viewpoints that are designed to capture different stakeholders' areas of interest. These are presented in an overarching domain meta-model that describes the definition of the viewpoints and their corresponding concepts and relationships [26. The UAF grid, or matrix, shows how the viewpoints correspond to different domains and model kinds within the UAF An illustration of the UAF matrix can be seen in Figure 2.1. 


\begin{tabular}{|c|c|c|c|c|c|c|c|c|c|c|c|}
\hline Mode ls & $\begin{array}{c}\text { Taxonomy } \\
\text { Tx }\end{array}$ & $\begin{array}{c}\text { Structure } \\
\mathrm{Sr}\end{array}$ & $\begin{array}{c}\text { Connectivity } \\
\text { Cn }\end{array}$ & $\begin{array}{c}\text { Processes } \\
\text { Pr }\end{array}$ & $\begin{array}{c}\text { States } \\
\text { St }\end{array}$ & $\begin{array}{l}\text { Interaction } \\
\text { Scenarios Is }\end{array}$ & $\begin{array}{c}\text { Information } \\
\text { If }\end{array}$ & $\begin{array}{c}\text { Parameters } \\
\text { Pm }\end{array}$ & $\begin{array}{c}\text { Constraints } \\
\mathrm{Ct}\end{array}$ & $\begin{array}{c}\text { Roadmap } \\
\text { Rm }\end{array}$ & $\begin{array}{c}\text { Traceability } \\
\text { Tr }\end{array}$ \\
\hline $\begin{array}{l}\text { Metadata } \\
\text { Md }\end{array}$ & $\begin{array}{c}\text { Metadata } \\
\text { Taxonomy } \\
\text { Md-Tx }\end{array}$ & $\begin{array}{c}\text { Metadata } \\
\text { Structure } \\
\text { Md-Sr }\end{array}$ & \begin{tabular}{|c|} 
Metadata \\
Connectivity \\
Md-Cn \\
\end{tabular} & $\begin{array}{c}\text { Metadata } \\
\text { Processes } \\
\text { Md-Pr }\end{array}$ & $\begin{array}{c}\text { Metadata } \\
\text { States } \\
\text { Md-St } \\
\end{array}$ & - & \multirow{10}{*}{$\begin{array}{c}\text { Conceptual } \\
\text { Data } \\
\text { Model, } \\
\text { Logic Data } \\
\text { Model, }\end{array}$} & \multirow{10}{*}{\begin{tabular}{|c} 
Environment \\
Pm-En \\
\\
\\
\\
\\
Measurements \\
Pm-Me
\end{tabular}} & $\begin{array}{c}\text { Metadata } \\
\text { Constraints } \\
\text { Md-Ct }\end{array}$ & $\begin{array}{c}\text { Metadata } \\
\text { Roadmap } \\
\text { Md-Rm } \\
\end{array}$ & $\begin{array}{c}\text { Metadata } \\
\text { Traceability } \\
\text { Md-Tr } \\
\end{array}$ \\
\hline $\begin{array}{c}\text { Strategic } \\
\text { St }\end{array}$ & $\begin{array}{c}\text { Strategic } \\
\text { Taxonomy } \\
\text { St-Tx }\end{array}$ & $\begin{array}{c}\text { Strategic } \\
\text { Structure } \\
\text { St-Sr }\end{array}$ & $\begin{array}{c}\text { Strategic } \\
\text { Connectivity } \\
\text { St-Cn }\end{array}$ & - & $\begin{array}{l}\text { Strategic } \\
\text { States } \\
\text { St-St }\end{array}$ & - & & & $\begin{array}{c}\text { Strategic } \\
\text { Constraints } \\
\text { St-Ct }\end{array}$ & \begin{tabular}{|c|} 
Strategic \\
Deployment \\
St-Rm \\
\\
Strategic Phasing \\
St-Rm
\end{tabular} & $\begin{array}{c}\text { Strategic } \\
\text { Traceability } \\
\text { St-Tr }\end{array}$ \\
\hline $\begin{array}{c}\text { Operational } \\
\text { Op }\end{array}$ & $\begin{array}{c}\text { Operational } \\
\text { Taxonomy } \\
\text { Op-Tx }\end{array}$ & $\begin{array}{c}\text { Operational } \\
\text { Structure } \\
\text { Op-Sr }\end{array}$ & $\begin{array}{c}\text { Operational } \\
\text { Connectivity } \\
\text { Op-Cn }\end{array}$ & $\begin{array}{c}\text { Operational } \\
\text { Processes } \\
\text { Op-Pr }\end{array}$ & $\begin{array}{c}\text { Operational } \\
\text { States } \\
\text { Op-St }\end{array}$ & $\begin{array}{c}\text { Operational } \\
\text { Interaction } \\
\text { Scenarios } \\
\text { Op-Is }\end{array}$ & & & $\begin{array}{c}\text { Operational } \\
\text { Constraints } \\
\mathrm{Op}-\mathrm{Ct}\end{array}$ & 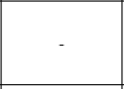 & $\begin{array}{c}\text { Operational } \\
\text { Traceability } \\
\text { Op-Tr }\end{array}$ \\
\hline $\begin{array}{l}\text { Services } \\
\mathrm{Sv}\end{array}$ & $\begin{array}{l}\text { Service } \\
\text { Taxonomy } \\
\text { Sv-Tx }\end{array}$ & $\begin{array}{c}\text { Service } \\
\text { Structure } \\
\text { Sv-Sr }\end{array}$ & $\begin{array}{c}\text { Service } \\
\text { Connectivity } \\
\text { Sv-Cn }\end{array}$ & $\begin{array}{c}\text { Service } \\
\text { Processes } \\
\text { Sv-Pr }\end{array}$ & $\begin{array}{l}\text { Service } \\
\text { States } \\
\text { Sv-St }\end{array}$ & $\begin{array}{c}\text { Service } \\
\text { Interaction } \\
\text { Scenarios } \\
\text { Sv-Is } \\
\end{array}$ & & & $\begin{array}{l}\text { Service } \\
\text { Constraints } \\
\text { Sv-Ct }\end{array}$ & $\begin{array}{c}\text { Service } \\
\text { Roadmap } \\
\text { Sv- } \mathrm{Rm}\end{array}$ & $\begin{array}{c}\text { Service } \\
\text { Traceability } \\
\text { Sv-Tr }\end{array}$ \\
\hline $\begin{array}{c}\text { Personnel } \\
\text { Pr }\end{array}$ & $\begin{array}{l}\text { Personnel } \\
\text { Taxonomy } \\
\text { Pr-Tx }\end{array}$ & $\begin{array}{c}\text { Personnel } \\
\text { Structure } \\
\text { Pr-Sr }\end{array}$ & $\begin{array}{c}\text { Personnel } \\
\text { Connectivity } \\
\text { Pr-Cn }\end{array}$ & $\begin{array}{c}\text { Personnel } \\
\text { Processes } \\
\text { Pr-Pr }\end{array}$ & $\begin{array}{c}\text { Personnel } \\
\text { States } \\
\text { Pr-St }\end{array}$ & $\begin{array}{c}\text { Personnel } \\
\text { Interaction } \\
\text { Scenarios } \\
\text { Pr-Is }\end{array}$ & & & \begin{tabular}{|c|} 
Competence, \\
Drivers, \\
Performance \\
Pr-Ct \\
\end{tabular} & $\begin{array}{c}\text { Personnel } \\
\text { Availability, } \\
\text { Personne1 } \\
\text { Evolution, } \\
\text { Personnel } \\
\text { Forecast } \\
\text { Pr-Rm }\end{array}$ & $\begin{array}{c}\text { Personnel } \\
\text { Traceability } \\
\text { Pr-Tr }\end{array}$ \\
\hline $\begin{array}{c}\text { Resources } \\
\text { Rs }\end{array}$ & $\begin{array}{l}\text { Resource } \\
\text { Taxonomy } \\
\text { Rs-Tx }\end{array}$ & $\begin{array}{c}\text { Resource } \\
\text { Structure } \\
\text { Rs-Sr }\end{array}$ & $\begin{array}{c}\text { Resource } \\
\text { Connectivity } \\
\text { Rs-Cn }\end{array}$ & $\begin{array}{c}\text { Resource } \\
\text { Processes } \\
\text { Rs-Pr }\end{array}$ & $\begin{array}{c}\text { Resource } \\
\text { States } \\
\text { Rs-St }\end{array}$ & $\begin{array}{c}\text { Resource } \\
\text { Interaction } \\
\text { Scenarios } \\
\text { Rs-Is }\end{array}$ & & & \begin{tabular}{|c|} 
Resource \\
Constraints \\
Rs-Ct
\end{tabular} & $\begin{array}{l}\text { Resource } \\
\text { evolution, } \\
\text { Resource } \\
\text { forecast } \\
\text { Rs-Rm }\end{array}$ & $\begin{array}{c}\text { Resource } \\
\text { Traceability } \\
\text { Rs-Tr }\end{array}$ \\
\hline $\begin{array}{l}\text { Security } \\
\text { Sc }\end{array}$ & $\begin{array}{l}\text { Security } \\
\text { Taxonomy } \\
\text { Sc-Tx }\end{array}$ & $\begin{array}{c}\text { Secunity } \\
\text { Structure } \\
\text { Sc-Sr }\end{array}$ & \begin{tabular}{|c|} 
Security \\
Connectivity \\
Sc-Cn \\
\end{tabular} & $\begin{array}{c}\text { Security } \\
\text { Processes } \\
\text { Sc-Pr }\end{array}$ & - & - & & & $\begin{array}{c}\text { Security } \\
\text { Constraints } \\
\mathrm{Sc}-\mathrm{Ct}\end{array}$ & - & $\begin{array}{c}\text { Security } \\
\text { Traceability } \\
\text { Sc-Tr }\end{array}$ \\
\hline $\begin{array}{c}\text { Projects } \\
\text { Pj }\end{array}$ & $\begin{array}{c}\text { Project } \\
\text { Taxonomy } \\
\text { Pi-Tx }\end{array}$ & $\begin{array}{c}\text { Project } \\
\text { Structure } \\
\text { Pi-Sr }\end{array}$ & \begin{tabular}{|c|} 
Project \\
Connectivity \\
Pi-Cn \\
\end{tabular} & $\begin{array}{c}\text { Project } \\
\text { Processes } \\
\text { Pi-Pr }\end{array}$ & - & - & & & - & $\begin{array}{c}\text { Project } \\
\text { Roadmap } \\
\text { Pi-Rm } \\
\end{array}$ & $\begin{array}{c}\text { Project } \\
\text { Traceability } \\
\text { Pi-Tr } \\
\end{array}$ \\
\hline $\begin{array}{l}\text { Standards } \\
\text { Sd }\end{array}$ & $\begin{array}{l}\text { Standards } \\
\text { Taxonomy } \\
\text { Sd-Tx }\end{array}$ & $\begin{array}{c}\text { Standards } \\
\text { Structure } \\
\text { Sd-Sr }\end{array}$ & - & - & - & - & & & - & $\begin{array}{c}\text { Standards } \\
\text { Roadmap } \\
\text { Sd-Rm }\end{array}$ & $\begin{array}{c}\text { Standards } \\
\text { Traceability } \\
\text { Sd-Tr } \\
\end{array}$ \\
\hline $\begin{array}{c}\text { Actual } \\
\text { Resources } \\
\text { Ar }\end{array}$ & & $\begin{array}{c}\text { Actual } \\
\text { Resource } \\
\text { Structure } \\
\text { Ar-Sr }\end{array}$ & \begin{tabular}{|c|} 
Actual \\
Resources \\
Connectivity \\
Ar-Cn \\
\end{tabular} & \multicolumn{3}{|c|}{ Simulation } & & & $\begin{array}{l}\text { Parametric } \\
\text { Execution/ } \\
\text { Evaluation }\end{array}$ & - & - \\
\hline \multicolumn{12}{|c|}{ Dictionary Dc } \\
\hline \multicolumn{12}{|c|}{ Summary \& Overview Sm-Ov } \\
\hline & & & & & Requ & nents Req & & & & & \\
\hline
\end{tabular}

Figure 2.1 The Unified Architecture Framework (UAF) matrix describing how the different viewpoints correspond to domains and model kinds. Adapted from 26 .

The different viewpoints are each associated with models designed to describe different areas of interest in an UML or SysML manner. The Strategic Taxonomy (St-Tx) in Figure 2.1 can, for example, be used to list all the capabilities of an SoS in question 27. Besides being used for modelling SoS s from different stakeholder viewpoints, the UAF can also been used to perform trade studies for SoS architecture development, as explained in 28]. One difference with the UAF compared with DoDAF and MODAF is that the UAF is designed to capture system architecture descriptions not just in the defence sector, but in commercial sectors as well.

\subsubsection{System of Systems Modelling and Simulation}

MBSE and architecture frameworks are one of many ways to model SoSs. A desired outcome when modelling SoS $\$$ is to understand possible emergent behaviours. Emergent behaviours are found at both system and SoS levels, and 
are important to understand in early development. According to [9], emergent behaviours are foreseen and appropriately tested during development for singular systems. However, these are harder to foresee in $[\mathrm{SoS} s$, as they must be rich in emergent behaviour to achieve a broad range of capabilities. In SoSs, all emergent behaviour cannot deliberately be designed in and there is always a risk of unintended consequences that are not discovered during testing [9]

The INCOSE Systems Engineering Handbook elaborates on the understanding of emergence by referring to complicated versus complex systems [3]. A complicated system can be understood by breaking it down into parts and then reassembling the parts to get an overall understanding of the whole. Consequently, the fixed relationships in a complicated system allow for reasonably reliable predictions of the system's characteristics and emergence. However, this is not as straightforward in complex systems. Here, the interconnections between the parts give rise to emergent properties that may disappear if the system is broken down and investigated as individually isolated parts. Different simulation approaches can however be used to facilitate the understanding of emergent behaviours in complex systems and $\mathrm{SoS}_{\mathbf{p}}$. System dynamics is an approach that can be used to investigate and increase the understanding of systems through simulations 29. It can also be used to indicate how desired emergent behaviours of an SoS can be achieved. Agent-Based Simulations (ABS) can be used to produce and analyse complex emergent behaviours in SoSs. ABS can thereby be used to enhance the understanding of SoS dynamics and performances in the early stages of system design [30]. Another approach that has been used to model systems and SoSs, in a similar way to MBSE. involves using ontologies. This is further explained in section 2.3 .2

\subsection{Ontology}

Ontology is a formal and explicit representation of a given domain that involves knowledge of the included entities and the relationships between them [31]. A more formal definition is that an ontology is an "explicit specification of a conceptualization" 32]. Ontologies are, in this sense, a way of representing domain knowledge and managing it through a common understanding of the content 31. Figure 2.2 shows an illustration of an ontology that describes entities and the relationships that exist between them.

The creation of ontology models can be referred to as ontological engineering, and this includes descriptions of the languages, methods and principles that can be used for this purpose. An ontology can be implemented in different ontology languages, the most common of which are the Resource Description Framework (RDF) and the Web Ontology Language (OWL) [33. [OWL is based on RDF but has the advantage of being better equipped for description logics and constraints checking [34]. An ontology produced in OWL consists of individuals, classes, and their properties and relationships that together are used to describe concepts of the domain in question. OWL-implemented 


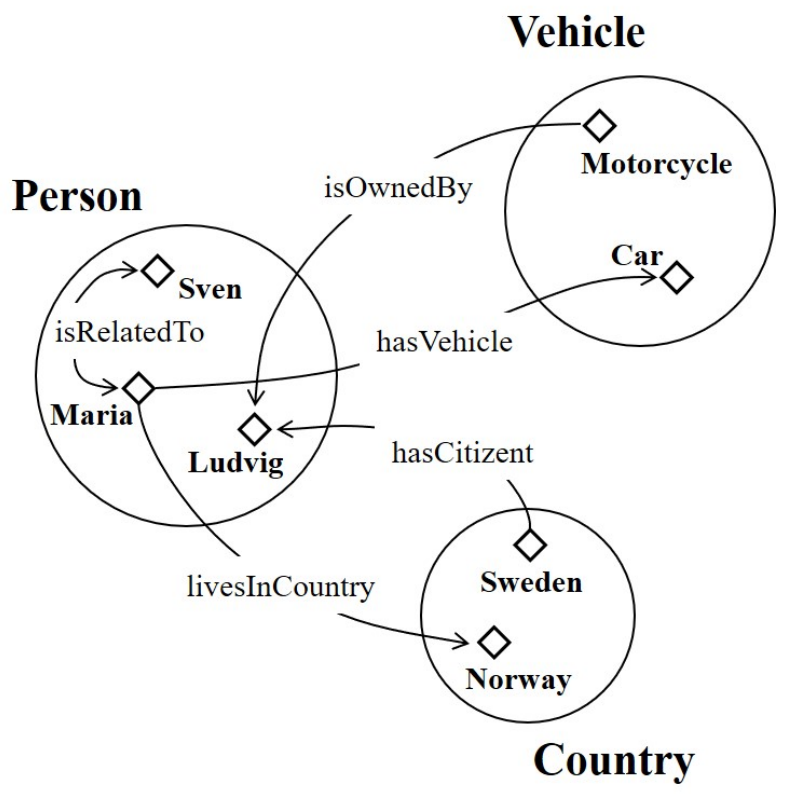

Figure 2.2 An illustration of an ontology that include entities and their corresponding relationships.

ontologies also feature the open world assumption and the non-unique naming assumption.

The open world assumption implies that new information about the domain can appear at any time, and no conclusions can therefore be drawn; more information that is simply not yet known could always come to light 33 . A closed world assumption regards non-existing data as false, while an open world assumption regards it as simply unknown. Consequently, no assumptions are made about incomplete data in an OWL ontology. The non-unique naming assumption simply implies that different entities within the ontology can be referred to using different names by people and organizations for example. The open world assumption and the non-unique naming assumption give OWL ontologies an advantage in terms of interoperability and scalability compared to relational databases, for example.

The Web Ontology Language - Description Logics (OWL-DL) is a subset of OWL and features description logic reasoning capabilities. Description logic reasoning, hereinafter referred to simply as reasoning, can check an implemented ontology model for inconsistencies. However, reasoning can also be used to infer complex relationships from simpler ones [35. Consequently, reasoning can be used to expand the captured knowledge and thereby contributes to the scalability of ontology models. Reasoning in OWL is based on the open 
world assumption, and there are different types of reasoners that each support different features [35, 36]. Automated reasoning over large ontologies does, however, require large computational resources and involves a cost in terms of computational time as shown in [37] and [38]. Computational resources are consequently a limiting factor when it comes to scalability through reasoning. However, there are various optimization techniques that can contribute to the efficiency of reasoning, as explained in [38]. Utilizing heuristics in the ontology can also contribute to the efficiency of reasoning in domains with a large number of axioms [39].

\subsubsection{Top-Level and Meta Ontologies}

The interoperability and scalability of an ontology can be further increased by utilizing a domain-neutral top-level ontology structure 40. A top-level ontology acts as a framework for organizing domain-specific ontologies. It also supports the creation of new ontologies, as well as the re-use of existing ones. Top-level ontologies can also be referred to as upper-level ontologies, and there are many examples of proposed structures for this purpose. A comparison between different top-level ontologies is presented in [41]. Consequently, ontologies can be used to describe other ontologies. This can be seen as a meta ontology structure, where more abstract and higher-level ontologies are used to describe lower-level and more general domain ontologies. A mid-level ontology fits in between top-level and domain ontologies. Such a mid-level ontology can, for example, describe a set of domain ontologies and their subsequent sub-ontologies. An example of this is a mid-level ontology describing vehicles. The corresponding more specific domain ontologies can then describe airborne vehicle systems, which in turn have sub-ontologies describing aircraft control surface actuation systems, for example. Figure 2.3 shows an illustration of what a hierarchy within a meta ontology structure could look like for the example just described.

A domain-specific ontology can, in this sense, describe certain areas of interest, such as individual systems, requirements or parts. Domain ontologies can be found in many areas of research, and an example of an ontology for aircraft design is presented in 42]. Another domain example is presented in [43], which describes an ontology for information systems interoperability. 


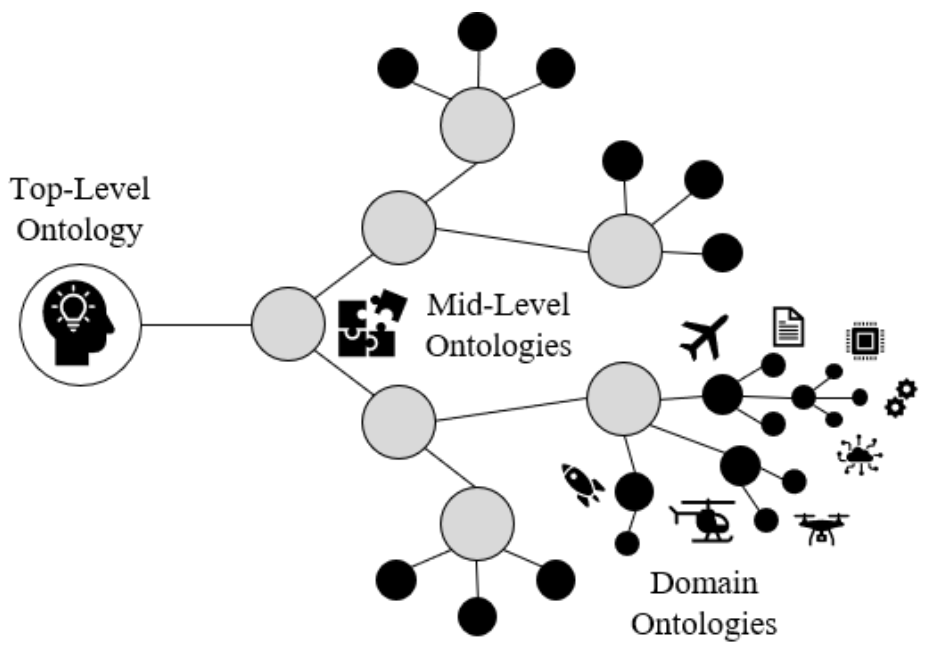

Figure 2.3 An illustration of the hierarchy between top-level, mid-level and domain ontologies in a meta ontology structure.

\subsubsection{Ontology-Based Systems Engineering}

Ontologies can be seen as complements to MBSE with modelling languages such as UML and SysML Ontology is used in a similar way to model and describe entities and their relationships in a domain. Ontologies do, however, feature an increased interoperability and scalability as previously mentioned. This comes from the ontologies' ability to describe a domain from different terminologies and viewpoints [44, 45]. Reasoning is also an advantage with ontologies, since it allows for automatic consistency checking and classification of relationships in the model. Ontology models have been used to represent relevant domain knowledge in SE, SoSE and capability engineering 46, 47, 48]. Ontologies have also been used to enable reasoning over SysML-represented content, to improve flexibility and to organize different domains in order to enhance the exchange of information 49, 50. SysML requirement diagrams can also be transformed into an OWL file to enhance the understanding of the semantic context, as illustrated by a case study in [51]. Consequently, the study in [51] also shows that UML and SysML models can be used to automatically generate an ontology. Using ontology in SE can be referred to as OntologyBased Systems Engineering (OBSE) There are many contributions that an ontology can bring to SE and Yang et al. present a summary of these together with a detailed state-of-the-art review of OBSE [52]. 


\subsection{Product and Engineering System Development}

Systems Engineering (SE) can be used to create systems and to develop new products, as mentioned in the introduction. Many SE approaches are still applicable in product development from an SoS perspective. Staack et al. suggest that holistic analyses of an SoS can give the functional requirements that must be fulfilled by the CS to meet the overarching capabilities [1]. These requirements can then be used as input for a continued product development process, where early system solutions are proposed through conceptual design studies. The many alternatives, which for example are able to fulfil overarching SoS capabilities and CS requirements, can be represented as elements in different design spaces.

\subsubsection{Design Space Explorations}

A design space contains all the possible solutions to a given design problem. The size of an available design space can be reduced by excluding areas where desired or specified requirements cannot be fulfilled. The feasible solutions can consequently be found by exploring the available design space of alternatives 53. Design space explorations are also used to increase the information and understanding about a new system in early development, thus reducing the overall uncertainty [54]. This can for example be done by investigating a system's sensitivity to changes in initial requirements or relevant design parameters. The overall goal of a design space exploration is to find the best valid solution that fulfils all requirements and design objectives as well as possible 55 .

The sheer size of a design space can be a challenge in explorations [56. Design space reductions are therefore an important aspect. This is especially true for SoS solutions that typically have large available design spaces due to their highly combinatoric nature. As previously mentioned, areas where non-valid solutions are found can quickly be ruled out by screening and excluding parts of the design space. Figure 2.4 illustrates a reduced design space representation.

As seen in Figure 2.4 a design space can be reduced by excluding areas that are unfeasible from different perspectives. This creates design subspaces of valid solutions that together intersect into a smaller area of overall suitable designs. This space can subsequently be further reduced by inserting design constraints, such as requirements or desired performances. The valid region then contains all the possible design options that are feasible and fulfil the given requirements. In contrast to reductions, design space expansions can be performed to add more possible options to the design and thereby open up new useful areas of the design space [57]. Parallels to the open world assumption in OWL can be drawn here, as a design space may contain more relevant information that simply is not known yet. The size of a design space can consequently be infinite, and the available design space of alternatives is better referred to as a design space representation as new alternatives may appear 


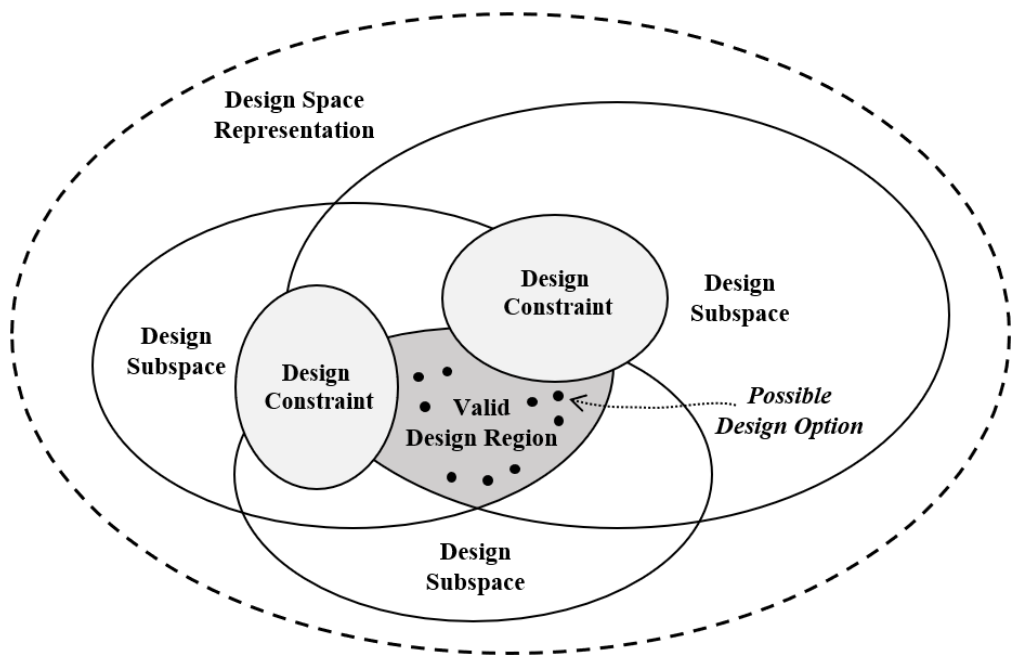

Figure 2.4 A design space representation that has been reduced by different valid subspaces and design constraints. Each point in the valid design region represents a valid design option.

through technological advances, for example. The non-stationary boundaries of the design space representation make product development complex from an SoS perspective, due to the evolutionary development and emergent behaviour characteristics.

Trade studies can be used to investigate how well the different elements in a design space meet the intended system objectives and requirements [58]. Such trade studies can for example be done by investigating how changes in design parameters and system requirements affect the overall design space and available solutions. The trade studies that can be performed span an available trade space. A trade space is a set of possible design options with completely enumerated design variables [59]. Modelling and simulations can then be used to evaluate the performance of each design option in a trade space. These trade space explorations give designers a perception of the available design space, and allow for a facilitated and more elaborate decision-making. They also allow stakeholders to see the trade-off between system characteristics in terms of cost and performance, for example.

Set-based design is a practice where single point solutions are not chosen until sufficient knowledge about a design space has been gained [60]. The design options and requirements are here kept flexible throughout the development process. Consequently, several possible design options are investigated simultaneously without committing to a specific solution. This enhances the flexibility of the design options and allow them to adapt over time. 


\subsubsection{Concept Generation Approaches}

A design space of alternatives can be generated in different ways. SE has many approaches for system development that still are applicable in an SoSE context. For example, a Quality Function Deployment (QFD) is an approach used to prioritize requirements and provide the relationships between technical requirements and stakeholder needs [53]. These derived requirements can then be broken down into a set of functional requirements describing what the system under development must be able to do. Consequently, the required functionality of the system can be used to choose suitable system elements that together meet the stated requirements.

\section{Function/Means Tree}

A Function/Means tree (F/M tree) is a method that can be used to perform functional breakdowns and concept generations [61]. An F/M tree describes a hierarchy of functions and the corresponding means that implement them. A means can also be referred to as an alternative, which for example can be a system solution that implements one or more specific functions. Figure 2.5 shows an example of an F/M tree structure.

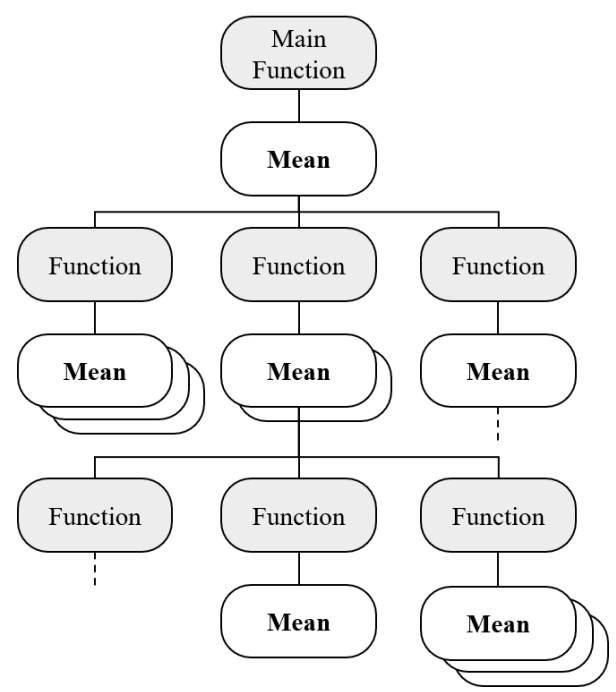

Figure 2.5 An example of a Function/Means tree ( $F / M$ tree) showing the hierarchy between alternating functions and means.

An F/M tree creates a hierarchy of functions and means, as illustrated in Figure 2.5. The top of the tree structure describes the main functions that the system should perform. The level beneath describes the different means or alternatives that can implement the main functions. Each means can subsequently be composed of lower-level functions that in turn are performed by 
lower-level means 61, 62]. This alternate decomposition can then be continued. The bottom level of means indicates sub-systems or system elements that may be used to fulfil the functions above. In this sense, a system concept corresponds to a set of particular means in the design space that the F/M tree spans.

\section{Matrix-Based Approaches}

Matrix-based approaches are commonly used to provide designers with an overview of an available design space and to generate concepts in product development. There are several examples of existing matrix-based approaches that can be used in an SoS perspective of a design process. QFD was previously mentioned as an alternative for translating customer needs into prioritized requirements of a system to be developed. A Design Structure Matrix (DSM) can be used to display the connectivities and interdependencies between elements within a system's design 63.

An F/M tree can also be used in conjunction with matrix-based approaches. One such approach is a morphological matrix, or a matrix of alternatives, which can be used to select alternatives for each function in the tree and thereby build up a concept for a new system. A morphological matrix provides a good overview for selecting suitable means for different functions, for example [64]. An Interactive Reconfigurable Matrix of Alternatives (IRMA) builds upon the information from a matrix of alternatives, and implements it in an interactive way that can be dynamically reconfigured depending on a designer's selections [53]. An IRMA also shows the incompatibilities within the design space and can be used to perform "what-if" analyses. Studies from Georgia Tech's Aerospace Design Laboratory (ASDL) have shown that matrix-based approaches, such as an IRMA, can be used to illustrate and create an available design space from knowledge captured in an ontology model [65]. In a similar way, an ontology and an IRMA can be used to model and prune a design space for cyber-physical systems in a conceptual design context [66]. The pruning of an available design space is an important aspect in system design from an SoS perspective. The available solutions can grow at an exponential rate due to the combinatorial nature of a complex system or SoS An IRMA can thereby help by dynamically keeping relevant parts of the design space active.

An additional benefit of an IRMA is that it provides an interactive visualization of the design space. This contributes to the early understanding of the interconnections and conflicts that exist in the design of a complex system [53. The visualization of a design space can enhance decision support by interactively illustrating the impact of a designer's decisions. Consequently, the field of visual analytics can support analyses and the perception of data in a design space [67. Visual analytics combined with "what-if" analyses can help increase understanding and support human reasoning by illustrating trade-offs between different requirements and performance measures in the available design space. 


\section{System of Systems and Ontology in Product Development}

Based on the five levels introduced in [1], this chapter illustrates a method and two related approaches that have been formed from the literature study and then been used to realize the corresponding parts illustrated in Figure 3.1 Consequently, this chapter shows how the method with its approaches can be used in product development from an SoS perspective.

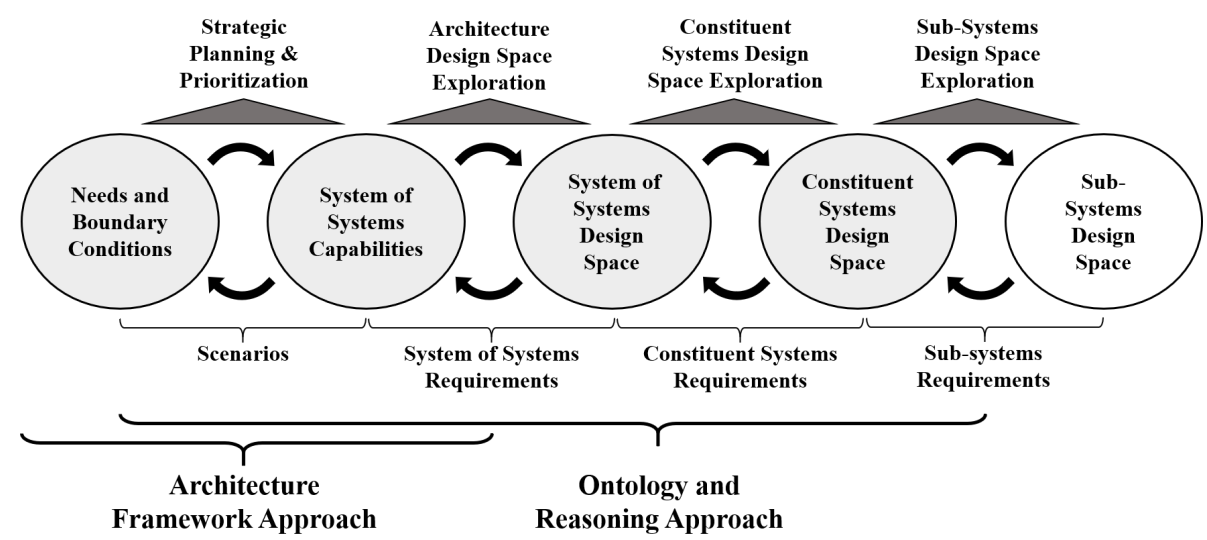

Figure 3.1 The corresponding levels of interests from [1] for which this thesis contributes realizations. Covered levels are marked in grey. 
The original versions of the two approaches from Figure 3.1 are described in detail in papers [I], [II] and [III]. However, these have been slightly updated in this thesis to better illustrate their use and to facilitate their interoperability in the presented method. Overall, the method can be used to traverse the different covered levels of the holistic SoS design process with the two approaches. This is shown in Figure 3.2 from a top-down perspective, starting with SoS needs.

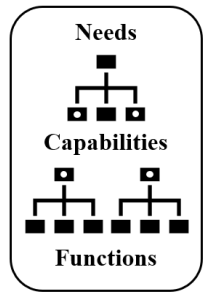

Architecture Framework

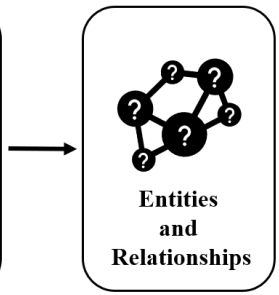

Ontology Representation

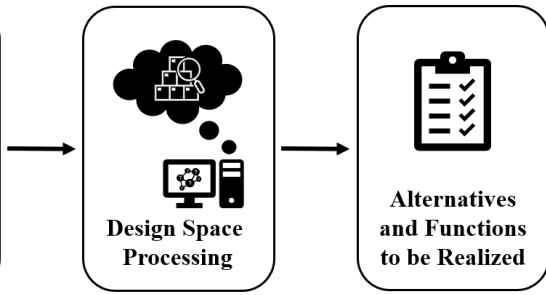

Description Logic Reasoning

\section{System of Systems'} Design Space

Figure 3.2 The overall method to realizing parts of a holistic SoS design process.

In Figure 3.2 the architecture framework approach is used to break down needs into corresponding capabilities and functions. The outcome from the breakdown is then represented using the ontology approach that incorporates reasoning. The ontology approach generates a reduced design space of alternatives or functions to be performed, which for example can act as inputs for a continued design process using other SE methods. The remainder of this chapter will describe these individual parts of the method in more detail.

\subsection{Search and Rescue as a Case Study}

Throughout this work, Search and Rescue (SAR) operations have been used as case studies to test the proposed approaches. SAR operations can be considered as typical examples of SoS $\$$ with a high degree of centralized control over the Constituent Systems (CS) involved. Furthermore, SAR can often include several types of rescue systems that may be influenced by the operational environment to a large extent. In this sense, the operational environment includes things such as weather and environmental conditions that may introduce changes in required capabilities and functions to be performed to meet stakeholder needs in a satisfactory way.

The SAR case studies used have been based on available information about SAR and SAR operations from the International Aeronautical and Maritime Search and Rescue (IAMSAR) manuals [68, 69, 70, and the Swedish Maritime Administration (SMA) [71, 72]. Figure 3.3 shows an example of a SAR scenario with different types of SAR assets. 


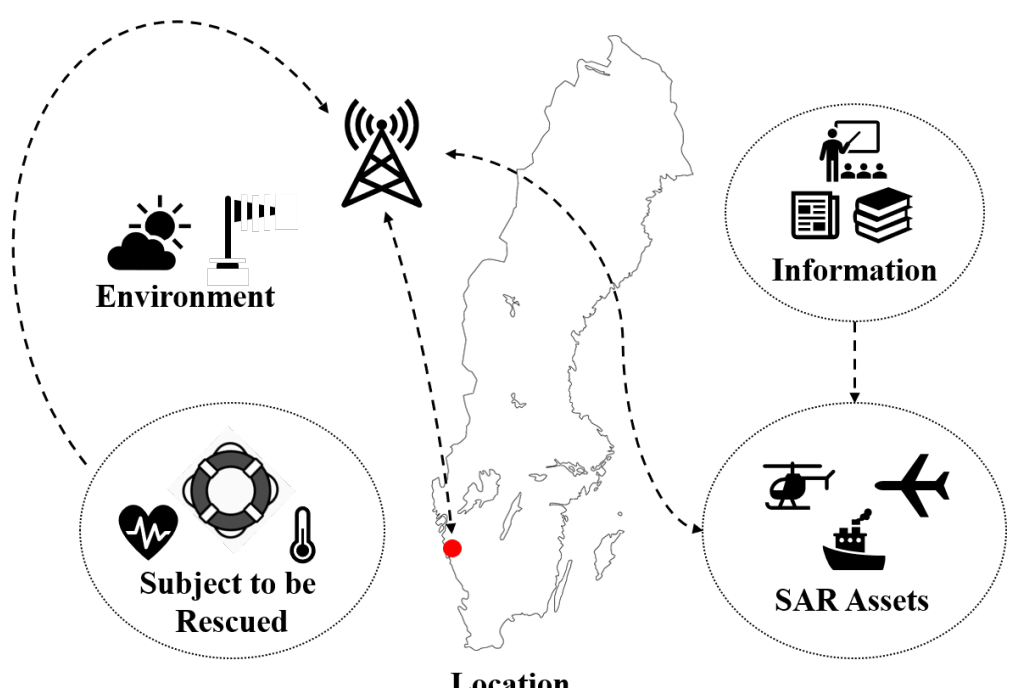

Figure 3.3 An example of a Search and Rescue (SAR) scenario off the coast of Sweden.

\subsection{Architecture Framework Approach}

The architecture framework approach was introduced in paper [III]. This approach shows how an architecture framework can be used to provide a standardized and consistent way of performing a breakdown of SoS needs into required capabilities and subsequent functions to be realized in a continued design process. SoS needs typically correspond to those of the involved stakeholders and any customers. In paper [III], four basic needs that any SAR system should meet were identified based on the IAMSAR manuals. These were listed as needs to:

1. Manage information

2. Coordinate search response

3. Coordinate rescue response

4. Provide assistance

These four basic needs were used as a starting point for the breakdown using the architecture framework. 


\subsubsection{Breakdown of System of Systems Needs Using the Uni- fied Architecture Framework}

As mentioned in chapter 2.2.2 architecture frameworks consist of different viewpoints that are designed to describe the architecture of complex systems and $\mathrm{SoS}$ s. They can consequently be used to describe models for areas of interest, such as capabilities and how they are related to operational activities. The Unified Architecture Framework (UAF) was chosen and used in the case study in paper [III], since it builds upon a combination of previous architecture frameworks. The intention of the approach has been to use the taxonomy and description of the UAF to provide a consistent and general way of understanding the hierarchical structure and relationships that lead down from an SoS need to a function to be performed by a CS

Based on this, different UAF viewpoints were used to create a general approach for understanding the governing relationships of an SoS needs breakdown. A UAF sample problem, [27], was used as both a guideline and a source of inspiration for utilizing the UAF in the case study in paper III]. The different UAF viewpoints that were used were as follows:

\section{- Strategic Taxonomy (St-Tx)}

Used to describe a taxonomy of available capabilities and their composition.

- Strategic Structure (St-Sr)

Can be used to describe the relationships between different capabilities listed in the St-Tx view.

- Strategic Traceability (St-Tr)

Can show how operational activities support represented capabilities.

- Operational Taxonomy (Op-Tx)

Used to list and describe a taxonomy of all operational activities. Similar to the St-Tx view, but used for operational activities instead of capabilities.

- Operational Processes (Op-Pr)

This view can be used to describe the relationships between operational activities and their corresponding sub-activities.

\section{- Operational Traceability (Op-Tr)}

Similarly to the St-Tr view, can be used to describe the mapping between operational activities and capabilities.

\section{- Resource Taxonomy (Rs-Tx)}

Can be used to describe a taxonomy of functions and their composition, for example. 


\section{- Resource Processes (Rs-Pr)}

This view shows the relationships between functions, and can also be used to describe their inputs and outputs.

\section{- Resource Traceability (Rs-Tr)}

Describes how the functions implement and map onto the different operational activities.

\section{- Parameters Environment (Pm-En)}

This view can be used to describe the environment and relevant environmental conditions of the domain in question.

The different views described above were then synthesized into a diagram describing how needs could be broken down in consecutive steps into capabilities, activities and functions to be performed. This diagram, also referred to as the architecture framework approach, can be seen in a UML format in Figure 3.4 .

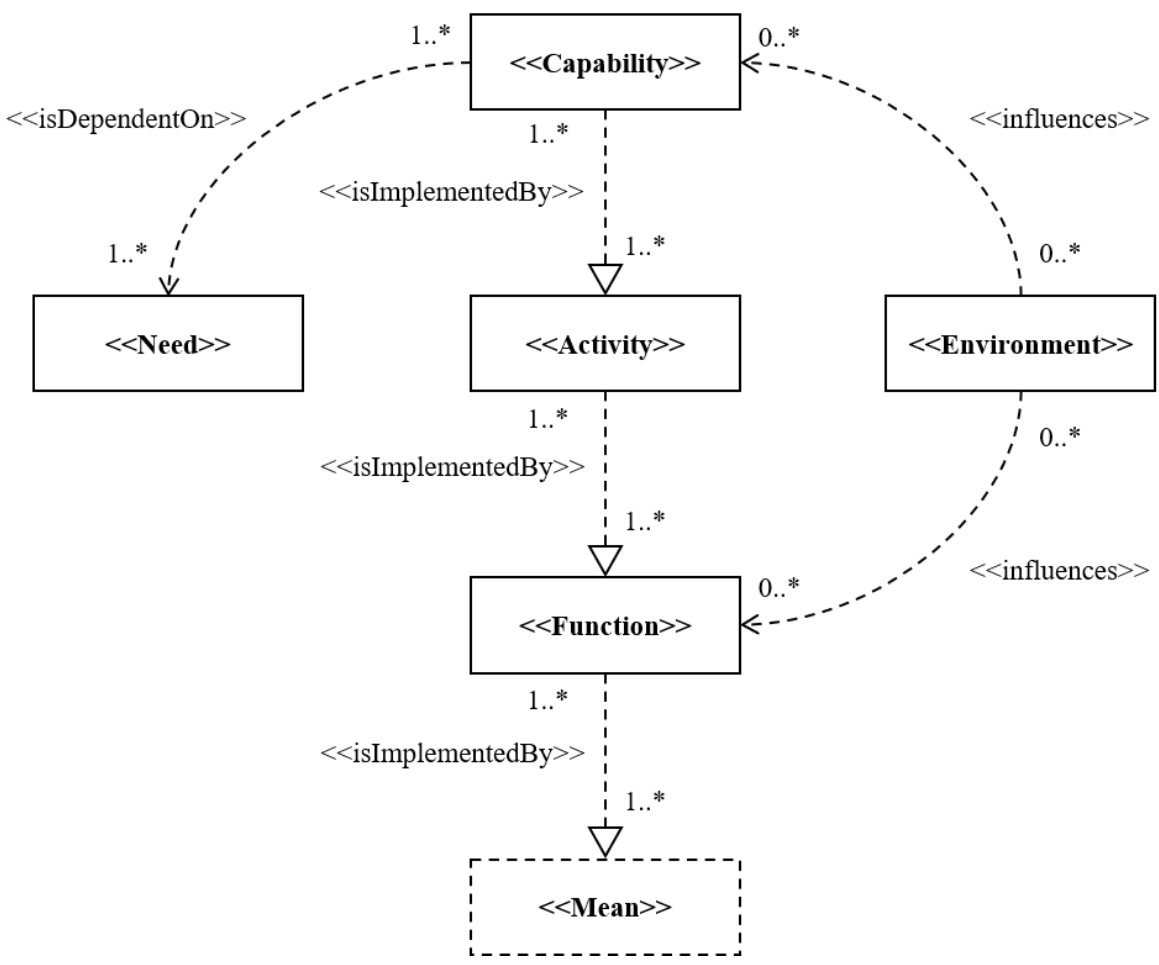

Figure 3.4 A UML diagram of the architecture framework approach, illustrating the breakdown process and the relationships between needs, capabilities, activities, functions, means and the environment. 
Needs can come from stakeholders or customers, and typically correspond to requests for solutions to problems that can be provided by a service in a defined environment. A stakeholder can, for example, be an individual or an organization with an interest in at least one phase of a complex system or an SoS described in the architecture framework. The system must be capable of satisfying the needs and thereby deliver the service. Consequently, the system must possess the capabilities to do so. In this sense, needs must always be associated with capabilities to be fulfilled, and a capability is consequently dependent on a corresponding need. A capability is defined as the ability to implement activities through a combination of different ways and means. Therefore, activities are implementations, or realizations, of capabilities. As Figure 3.4 shows, a capability can be implemented by at least one activity, and one or more activities can implement at least one capability in the inverse direction. An activity is implemented by one or more functions. The functions are in turn implemented by means or elements that correspond to CS and sub-systems, for example. Finally, the environment has an influence on the required functions and capabilities. An activity might consequently require different functions to successfully realize the intended capability, depending on the surrounding conditions. The definitions listed above are based on the information found in the UAF sample problem and documentation 27,73 .

\subsubsection{Outcome and Design Space}

The architecture framework approach outlined in section 3.2.1 results in a number of functions that are to be performed to realize the overarching capabilities required to satisfy the customer and stakeholder needs. Consequently, it creates a design space of functions to be performed that can be either realized using existing means or used as inputs for a continued design process. Further discussions on how the outcome can be used for this purpose are presented in chapter 4 Additionally, the outcome and design space of functions from the architecture framework approach can also be further processed by being represented in an ontology, as seen in Figure 3.2 .

\subsection{Ontology and Reasoning Approach}

Ontology and reasoning has been a common topic for all appended papers in this thesis. Ontology has here been used to represent entities and their relationships, similarly to how UML and SysML models are used. In this way, the ontology can correspond to a representation of an available design space for systems and SoS s. Description logic reasoning subsequently allows the design space to be processed, as this section will describe in more detail. 


\subsubsection{Building an Ontology for an SoS Design Space}

The ontology approach referred to in this thesis was first introduced in paper [I], and has been further refined and utilized in papers [II] and [II]. Paper [I] also proposed a process for building an ontology that represents an available SoS design space. Figure 3.5 shows a slightly updated version of this process.

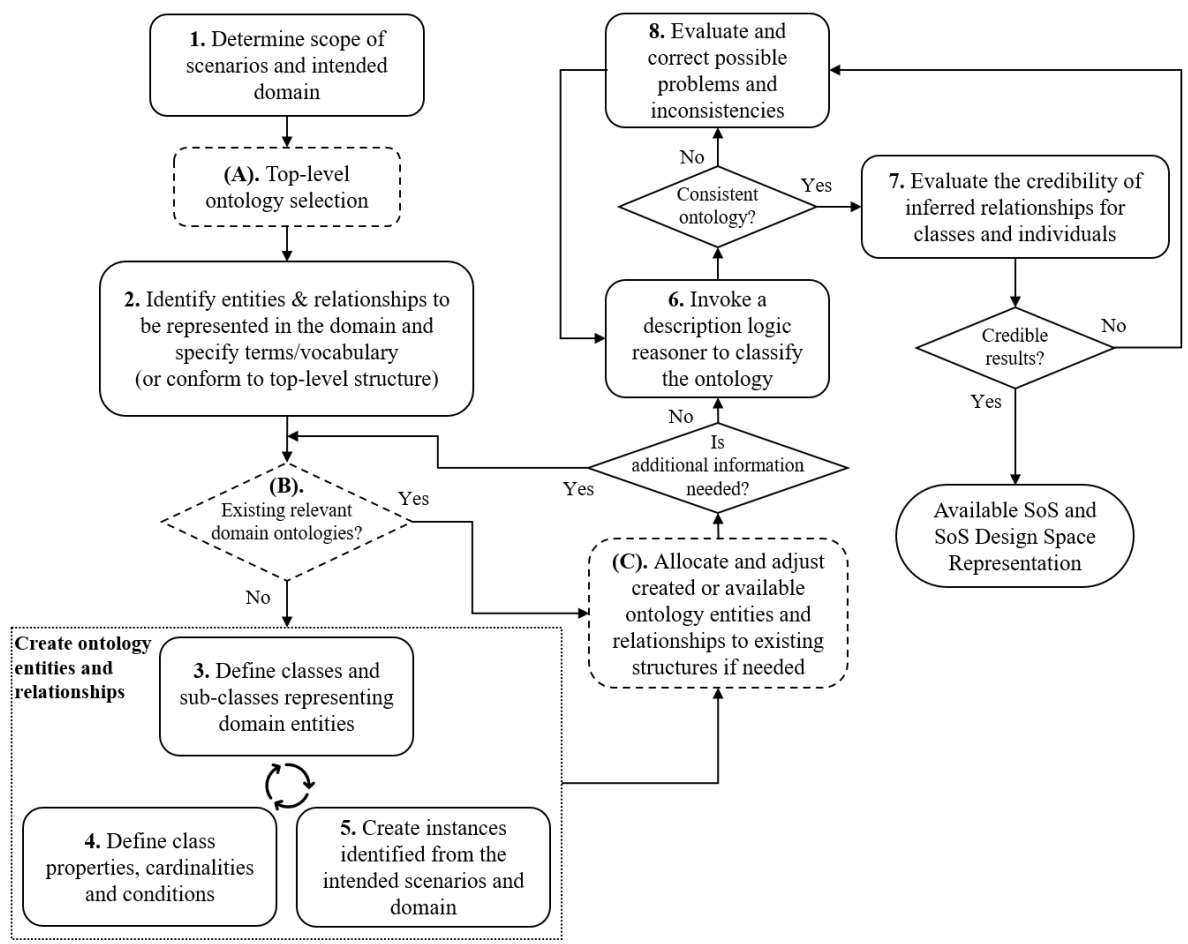

Figure 3.5 The ontology development process for generating a representation of an SoS design space. Updated from the version first introduced in paper [I]

The process in Figure 3.5 consists of eight steps, and has been partly based on the guidelines presented in [31] and [40]. The process is intended to be used with the Web Ontology Language (OWL) which supports reasoning, as mentioned in chapter 2.3 . The Protégé ontology editing software, [74], has been used to implement ontologies with the process from Figure 3.5 in all case studies in the appended papers.

\section{Step 1: What Should Be Modelled?}

The process in Figure 3.5 starts with the step of determining the scope of the scenarios and the intended domains to be modelled. This could be different SAR operations as shown in the case studies in papers [I] and [II], for exam- 
ple. The scope can also correspond to the outcome of a breakdown with the architecture framework approach as shown in paper [III].

\section{Step (A): Top-Level Ontology Selection}

An optional step before step two allows for the incorporation of a top-level ontology structure. As explained in 75 and briefly mentioned in chapter 2.3.1. top-level ontologies can bring several benefits, such as improved interoperability between different domain ontologies. Top-level ontologies, such as the Basic Formal Ontology (BFO) 75, 40], offers a predefined structure and hierarchy for representing domain knowledge.

\section{Step 2: Identify Relevant Entities and Relationships}

The second step of the process involves identifying the relevant entities and relationships that are to be represented in the ontology. From a SAR perspective, entities can include available assets, weather conditions, capabilities, regulations and more. Relevant entities to be represented can be identified via holistic analyses of possible scenarios for the intended domain and scope, for example. Terms and vocabularies in the ontology should be specified in a coherent way so that ambiguities in definitions are avoided. Top-level ontologies may include existing terms and vocabularies in their definitions, and the knowledge to be represented should conform with these to facilitate reusability.

\section{Step (B): Include Existing Domain Ontologies?}

The option for including existing domain ontologies is introduced before step 3 . The reason for this is that ontologies can suffer from a "reinvent-the-wheel" syndrome, where several ontologies are created for the same purpose [75]. Therefore, it is desirable to consider using existing ontologies in the process to avoid creating a new and redundant one 31. If existing ontologies are to be used, they should be adjusted to fit the intended formalism and structure of the ontology under development, as explained in step (C).

\section{Step 3: Create Classes}

Step 3 of the process involves the creation of ontology classes from the entities identified in step 2. Ontology classes are implemented in a hierarchical structure with classes that can have subclasses, which in turn have their own subclasses and so on. The relationships between classes in the hierarchy structure are of an "is a" nature. This means that a sub-class is a specialization of its super class, and that the sub-class consequently inherits the properties of the superclass. For example, an aeroplane is an airborne vehicle, which in turn is a vehicle that is a system that is an entity. Saying that all entities have a mass property, for example, implies that all aeroplanes must also have mass properties. Figure 3.6 shows an illustration of an is a hierarchy. 


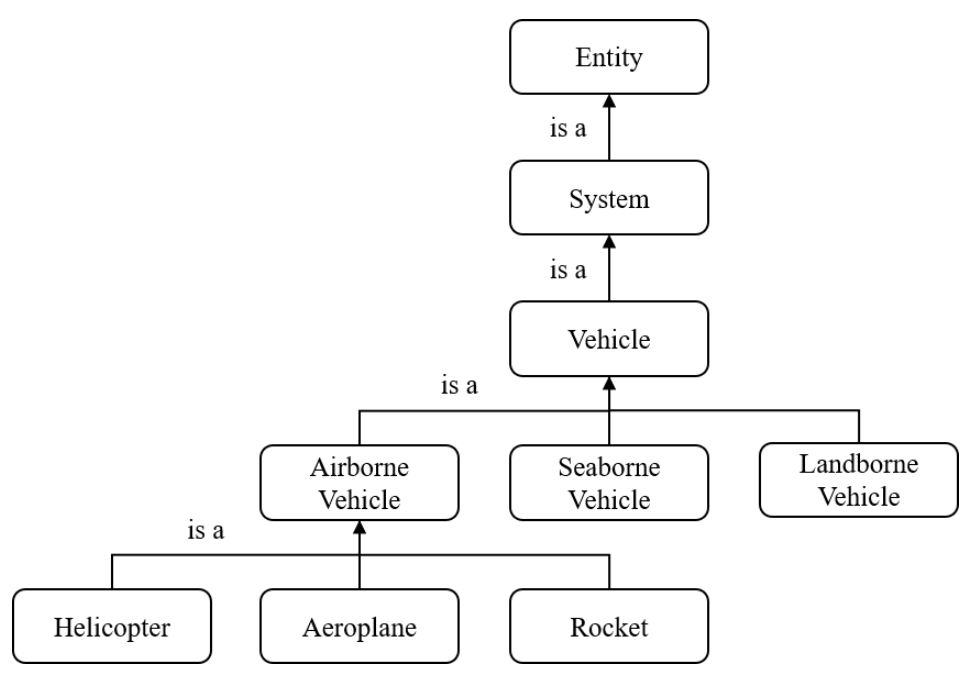

Figure 3.6 A class hierarchy illustrating the "is a" relationship.

Different approaches can be used when establishing a class hierarchy, as described in [31]. Due to the open world and non-unique naming assumption in OWL, it is also important that classes that are not equal to each other are defined as disjoint for the subsequent invocation of the reasoner. A helicopter class should, for example, be disjoint with a weather condition class, since a helicopter cannot possibly be a type of weather phenomenon.

\section{Step 4: Create Relationships}

This step is used to define all relationships that are to be represented in the ontology. Ontology relationships describe how classes and individuals are related to each other, but can also describe structures, properties and data values, for example. Relationships are described using object and data properties in OWL Object properties are used to describe relationships between ontology classes and instances, while data properties are used to describe how classes and instances relate to data, such as numbers and strings. Cardinality specifications can be used to describe the number of relationships that classes have in a min., max. or exact logic. OWL includes many more options for defining relationships using object and data properties, and further explanations and details are found in [31] and 35].

Additionally, ontology classes can be defined as either primitive or defined. The differences between these two types are what OWL refers to as necessary and sufficient conditions. A primitive class only contains necessary conditions. These can, for example, explicitly describe how an entity is built up in terms of relationships within the ontology. A defined class contains at least one necessary and sufficient condition. In short, defined classes allow for automated 
classification and processing of implicit relationships between classes and individuals in the ontology using a reasoner. More information about this, as well as examples, can be found in [35] and in the case studies in papers [I], [I] and [III.

\section{Step 5: Create Instances}

Individuals, also sometimes referred to as instances, are defined as "the most specific concepts represented in a knowledge base" [31. Consequently, individuals represent the lowest granularity or level of detail in the modelled domain of the ontology. Classes can be seen as collections of corresponding individuals. Relationships between classes thereby describe general relationships between their individuals. Individuals can also be members of more than one class. In a SAR context, an instance can be a helicopter of a specific type that is a member of the helicopter class in Figure 3.6, for example.

As just shown, steps 3 to 5 are used to create the entities and relationships in the ontology model. These three steps have no specific starting point, and can typically be performed in an iterative manner until the desired ontology representation of the domain is achieved.

\section{Step (C): Adjust Entities and Relationships}

This optional step is to be utilized if top-level or existing domain ontologies are being used. The previously represented entities and relationships from steps 3-5 should here be allocated and adjusted into the existing ontology structure provided by any top-level or domain ontologies. Steps 3-5 and (C) can then be revisited if additional information is needed to model the domain in the intended way.

\section{Step 6: Invoke the Reasoner}

Once the relevant entities and their relationships have been modelled, a reasoner can be invoked. The reasoner will classify and check the implemented ontology for inconsistencies, but it will also build up a new inferred ontology. The unclassified ontology is referred to as the asserted ontology, and corresponds to the outcomes from steps 3-5 that have not been processed by the reasoner. The inferred ontology will be built up based on the defined relationships, properties and conditions in the asserted ontology model. Defined ontology classes will be populated with classes and instances that fulfil the necessary and sufficient conditions to be regarded as members of the defined class. The reasoner can consequently draw conclusions about implicit relationships in the ontology and restructure it accordingly.

Step 8 of the process should be performed if the reasoner classifies the ontology model as inconsistent. 


\section{Step 7: Assess Inferences}

Step 7 should be performed to assess and evaluate the inferences made in the ontology model and its defined classes. The ontology may prove to be consistent but include unwanted or unreasonable results. The reasoner will make the inferences based on the modelled domain and its implemented relationships. Consequently, any modelling errors from steps 3-5 might result in a consistent ontology but with erroneous inferences from the modeller's perspective. If such inferences are found, or if the ontology is classified as inconsistent, step 8 must be performed.

\section{Step 8: Correct Model Errors or Inconsistencies if Needed}

Step 8 of the process should only be performed if the ontology is classified as inconsistent or if unwanted and erroneous inferences have been made according to the ontology modeller. Corrections can be made by revisiting steps 3-5 and consequently adjusting the implemented classes' and individuals' relationships, properties and conditions. Unwanted, erroneous or simply unreasonable results can be further investigated using description logic querying. The inferred ontology is here used to answer "questions" about the modelled domain and its classes and instances [76]. Consequently, description logic querying can give the modeller an indication and an explanation of why such inferences have been made by the reasoner. Inconsistencies can be hard to identify, and different ontology debuggers for OWL may be useful for finding the source of any inconsistencies in the ontology [77].

\section{Ontology Process Outcome}

The outcome from the ontology process in Figure 3.5 is a knowledge representation and a model of the entities and relationships that exist in the chosen domain. This knowledge representation can correspond to an initial design space representation for an $\mathrm{SoS}$ with, for example, available SAR assets to perform a mission, as the case studies in papers [I] and [II] show. However, it can also correspond to a design space of functions to be performed to meet overarching capabilities and needs, as described in paper [III. Additionally, the case study in paper [II] has shown how the proposed process can be used to extend and incorporate an existing ontology structure, namely the one from paper [I]. The case study in paper [II] has also shown how the process can be reiterated to include more information than initially specified.

The design space representation generated via the process can then be further processed using the reasoner, as the next section will explain in more detail. 


\subsubsection{Reasoning and Design Space Processing}

Reasoning has thus far mainly been used to classify and check the ontology representation for inconsistencies in the process from Figure 3.5 Another important capability that a reasoner provides is that it can infer implicit relationships in the ontology model, as briefly mentioned above. Consequently, reasoning can be used to further process the design space generated using the ontology development process. Reasoning has been used for this purpose in all papers appended to this thesis.

\section{Design Space Reduction}

The general approach for processing the design space has been established by modelling defined classes with necessary and sufficient conditions in the ontology asking for user-defined needs, requirements and desired performances, for example. Reasoning has then been used to automatically populate the defined classes with the classes and instances that are able to fulfil the necessary and sufficient conditions. This approach thereby filters the available design space and results in a reduced design space representation. The conditions in the defined classes can here ask for entities with relationships to certain capabilities or entities with certain data properties, for example, such as a rescue capacity above a specified number as shown in paper [I]. The reasoner can consequently filter out irrelevant solutions and thereby parts of the design space representation in the defined classes. However, this does not remove information from the overall design space, and the conditions in the defined classes can always be adjusted to open up or narrow down the size of the design space reduction. Figure 3.7 shows an illustration of a design space reduction using defined ontology classes.

The defined classes marked with grey backgrounds in Figure 3.7 create a union which represents the area where included instances and classes are able to fulfil the conditions of the two defined classes. Consequently, the available reduced design space is represented by the inferred sub-classes and individuals of the defined classes that have been used to query the ontology. More information and illustrative examples of how defined ontology classes and their necessary and sufficient conditions are created to perform design space reductions can be found in the case studies in papers [I], II] and [II]. Additionally, paper III elaborates on the possibility of not finding any solutions for the conditions in the defined classes, and how these conditions can consequently be used as inputs for a continued design process. This is also further discussed in section 3.3 .3 


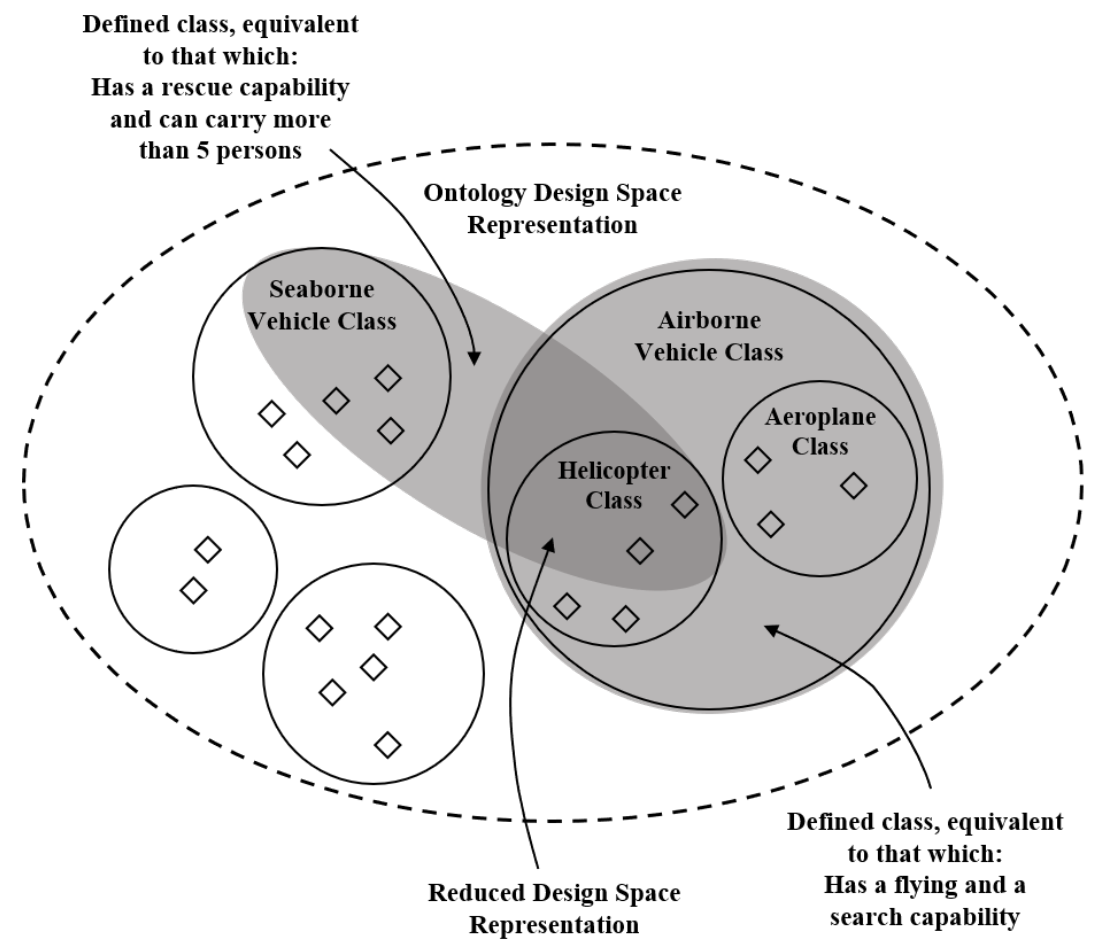

Figure 3.7 An illustration of an ontology represented design space with defined classes marked with grey backgrounds. Classes are represented by circles and individuals by diamonds.

\section{Design Space Expansion}

The reasoner can also be used to expand the available design space using implicit relationships in the ontology representation. Examples of this have been both shown and discussed in the case studies in all appended papers. For example, a new entity can be added to the ontology with only one property stating that it has the capability to fly. The reasoner can then infer that this new entity must be some sort of airborne vehicle, since these have the capability to fly. The new entity can consequently be regarded as belonging to the airborne vehicle class and will thereby inherit the airborne vehicle class properties. These can be properties stating that all airborne vehicles have a weight, cruise speed, average fuel consumption, fulfilment of certain functions, and more. The reasoner can thereby infer and add more information to the newly added entity automatically. Consequently, the newly added entity can also be regarded as a solution to defined classes in a design space reduction context. However, using the reasoner to expand the ontology and infer implicit 
relationships adds to the cost in terms of computational time, as described in chapter 2.3 More details about how implicit information can increase the computational time for reasoning in OWL are explained and discussed in [76], where reasoning and inferred relationships are used to a high degree to build up an ontology.

Finally, the case study in paper III] also shows how an initial ontology representation created from the architecture framework approach can be expanded with additional information before a design space reduction is performed. Implicit relationships are also used here to sort ontology classes into the modelled class hierarchy.

\subsubsection{Ontology Approach Outcome and Opportunities}

Overall, the ontology approach presented in this section results in a reduced design space of alternatives or functions to be performed in order to meet overarching needs and capabilities. The approach can be used to give suggestions for both suitable systems and SoSs. Paper $[\mathrm{I}]$ discusses how the approach can be used on three different SoS types from a time perspective. The first is a near-term SoS perspective, where only existing solutions and how to best use them are investigated. Investigations of existing solutions have been the main focus of papers [I] and [II]. A mixed SoS perspective includes both existing and new solutions to be developed. Paper [III] presents how the approach can be used to give a reduced design space of functions to be performed. Paper III also discusses how existing solutions can be modified to meet certain functions and then collaborate with other existing solutions to create a valid SoS. In this sense, a new system does not have to be created. A long-term SoS perspective corresponds to one where the solutions are yet to be developed. The suggested functions to be performed from the ontology approach are here inputs for a continued design process that can be used to create new system and SoS solutions.

The case study in paper [II] shows how the ontology approach can be integrated with Agent-Based Simulations (ABS) to generate, reduce and evaluate an SoS design space. Different combinations of existing SAR assets were here generated from the ontology and then simulated to give the different SoS performances in terms of overall mission time and cost to find a rescue subject. Figure 3.8 shows an overview of the approach in paper [II]. More details about this approach are found in the method and case study in paper [II]. 


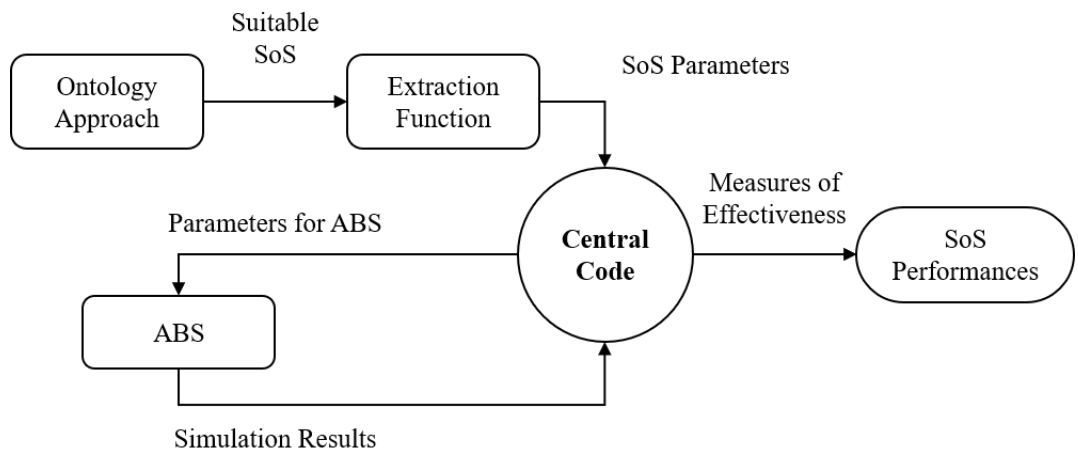

Figure 3.8 The approach used to connect ontology with Agent-Based Simulations $(A B S)$ in paper [II].

Paper III discusses opportunities for continuing the design process from the obtained design space of functions to be performed. In this case, the defined ontology classes that do not have any inferred solutions to conditions describing user-defined needs and requirements correspond to what a new system or SoS to be developed must do. One option for continuing the design process is to further break down required functions using an F/M tree that can subsequently be used to create different matrices for concept generation. These matrices may, for example, be those discussed in chapter 2.4.2 such as an Interactive Reconfigurable Matrix of Alternatives (IRMA) The outcome from a continued design process using an $\mathrm{F} / \mathrm{M}$ tree could also be used to expand the knowledge represented in the ontology model, which would correspond to an additional design space expansion. 


\section{4}

\section{Discussion}

The method, and its corresponding approaches described in chapter 3 has been used to provide partial realizations of several levels in the holistic SoS design process, as illustrated in Figure 3.1. Ontology is believed to be a suitable option for generating and processing the design spaces of the different levels. The appended papers have shown how the design space of alternatives for an SoS can be generated and reduced using ontology and reasoning. Also, paper III] shows how to obtain the functions to be performed, and elaborates on how these can be used for a continued design process. Consequently, paper [II] briefly touches upon the Constituent Systems (CS) design space level in Figure 3.1 The design space for CS and sub-systems should theoretically be processable in a similar way to how the SoS design space has been processed using ontology and reasoning. The ontology approach is consequently believed to be applicable at all levels of the holistic design process in Figure 1.2 Design space processing can therefore give suggestions on suitable sub-systems to perform functions as well, if they are modelled in the ontology representation.

The architecture framework approach has been used to break down a set of SoS needs into subsequent functions to be performed. It has thereby been used to traverse the two leftmost levels of the holistic design process in Figure 3.1. However, the approach has only incorporated a selection of viewpoints from the Unified Architecture Framework (UAF). It is possible that more levels can be covered with the approach if additional viewpoints are included. The UAF and other architecture frameworks, include many more considerations and viewpoints than those described in chapter 3.2.1 and this thesis. These include the use of existing resources and how best to use them from a Concept of Operations (CONOPS) perspective, for example. However, the goal of the architecture framework approach has, as previously mentioned, been to provide a consistent and standardized way of breaking down the needs to required capabilities and functions. Consequently, the used viewpoints have been deemed sufficient for this purpose. 
As mentioned in chapter 3.2 .2 the outcome of the breakdown also results in a design space of functions to be performed that, for example, can be used as inputs for a continued design process. The overall structure of the approach in Figure 3.4 is similar to the one used in a Function/Means tree (F/M tree). Functions and means are here alternated, as described in chapter 2.4 .2 , and the same procedure can consequently be performed on the outcome of the architecture framework approach and breakdown. An F/M tree is therefore a suitable option for a continued design process with functional decompositions and investigations of their possible realizations. Additionally, capabilities can be seen as special cases of functions, and can consequently be treated as the top-level, or main, functions in an F/M tree In this case, the activities are the means by which to implement the capabilities. Another important aspect in a breakdown using the architecture framework approach is the different scenarios in which a complex system or SoS is expected to be involved. Different scenarios can have new or different stakeholders and corresponding needs, which in turn might require additional capabilities and functions to be fulfilled. The design space of functions to be performed could consequently be explored by investigating different possible scenarios using the approach. Reoccurring capabilities and functions can thereby be identified and considered as the most important ones to fulfil in order to cover a range of different possible scenarios.

It is possible to perform initial design space explorations using the ontology approach as well. While no case study in the appended papers explicitly shows this, explorations can be performed by dynamically investigating how changes in the defined ontology classes affect the corresponding design space. Design space explorations can also be performed by investigating how changes in the definitions of all ontology individuals and classes influence the available solutions indicated by the defined classes. Several defined classes describing different conditions and user-defined needs can also be created in order to find the most common and persistent solutions in the different reduced design space representations. This is shown and discussed in the results of the case study in paper $[\mathbf{I}]$, where the individuals with the highest reoccurrence in the defined classes can be identified. Parallels to set-based design can also be drawn to the ontology approach here. The outcome represents a set of possible solutions in a reduced design space that always can be adjusted if desired or needed. Consequently, ontologies allow for a flexible representation of a design space and more knowledge about design solutions and options can be added at any time. As mentioned in chapter 2.4.1, design space explorations are performed to find the best solution to a given design problem. Consequently, the design space explorations that can be performed with the ontology approach are labelled as initial, since more considerations must be included. For example, the approach only gives suggestions for suitable solutions that fulfil the conditions, and not specifically for a single optimal solution. A continued evaluation process using simulation techniques such as Agent-Based Simulations (ABS) is one possible option for indicating the effectiveness of different solutions, as shown in paper 
[II]. The case study in paper [II] shows how a Pareto front of different SoS solutions can be obtained to illustrate the trade-off between detection time and overall mission cost. This case study is, however, only based on existing Search and Rescue (SAR) assets, and more extensive design and trade space explorations should be performed if a new system is to be developed. In this case, new concepts must be generated and modelled to enable testing through simulations, such as ABS to be included as options on a subsequent Pareto front illustrating design trade-offs.

Additional Systems Engineering (SE) approaches can be used to generate new concepts from requirements and desired properties derived from the approaches outlined in this thesis. An ontology can act as an overarching knowledge representation, where new information generated from such SE approaches can be stored and thereby increase the size of the design space representation, for example. The ontology approach and process can be reiterated to incorporate this new information in the ontology model. A comparison between design spaces and the open world assumption of ontologies was mentioned in chapter 2.4.1. The open world assumption makes the ontology representation flexible and scalable, since more information can be introduced at any time. It consequently coincides well with design space representations, where new options can be added as they become available through technology advancements, for example. The non-unique naming assumption is also beneficial in the flexibility and scalability perspective, since engineers can refer to entities with different names and notations. Meta-ontology structures were mentioned in chapter 2.3.1, together with top-level ontologies. A meta-ontology structure where relevant ontologies can be dynamically activated would be beneficial, from a scalability perspective, to the design space processing using the reasoner. The design space can consequently be kept at a manageable level where irrelevant information does not have to be processed by the reasoner. This can be regarded as a future project, on which chapter 6 will elaborate.

The ontology process in Figure 3.5 and chapter 3.3.1 has only been used with the Protégé ontology editing software [74 in the case studies of the appended papers. However, the ontology process and approach should be applicable in any tool that supports OWL and description logic reasoning as discussed in paper $[\mathrm{I}]$. There are also more methods for building ontologies that will result in similar knowledge representations to those generated by the approach in this thesis. It is also possible that the outcome of the ontology process in Figure 3.5 can be obtained with UML or SysML models. However, the benefit of having the knowledge represented in an ontology is that a reasoner can be used to automatically handle the complex relationships that can exist in even relatively small and low-fidelity representations, as discussed in paper [III. The fidelity levels of the case studies from the appended papers have been kept at a basic level. The presented approaches are, however, general in terms of fidelity and higher, or different, fidelity levels can theoretically be included with the presented approaches. Higher fidelity levels could include 
more information to be modelled in the ontology. The reasoner can aid in the ontology modelling by inferring implicit relationships. As mentioned in the previous chapter, more implicit relationships in the ontology do, however, increase computational time if the reasoner is heavily relied upon to build up a higher fidelity ontology. The ontology can also be entirely manually built up by explicit relationships, and more computational resources can thus be conserved for design space processing purposes with the reasoner. However, an important consideration with reasoning is how inferred relationships can be verified and deemed as correct. Steps 7-8 of the ontology process in chapter 3.3.1 explain that inferences should be assessed and corrected if needed. Inconsistencies and modelling errors might be easy to detect and correct for small representations in well-known domains. However, this might become a problem in large knowledge representations, where the designer might have limited knowledge about certain aspects of the domain and consequently cannot rely on statistics or intuition, for example. The verification and validation of inferred knowledge in the ontology is therefore an important topic for future work.

Furthermore, emergent behaviours of $\operatorname{SoS} \$$ are important to understand and chapter 2.2.3 has mentioned ABS as one possible option for this purpose. Another option could perhaps be to discover emergent properties using ontology and reasoning. The reasoner could infer implicit relationships revealing connections that an ontology modeller is unaware of. However, this does to a high degree depend on how the ontology is built up and the ontology modeller must in that case be able to verify that the inferred knowledge is correct, as mention previously. Consequently, emergent behaviours are probably better represented in an ontology model rather than identified.

Finally, the case studies of the appended papers have only been based on Search and Rescue (SAR) and this has been a delimitation of the thesis, as described in chapter 1.3 The approaches presented are, however, applicable to any $\mathrm{SoS}$ and have also been kept general for this purpose. Another SoS case study would generate a dissimilar set of needs than those listed in chapter 3.2 The architecture framework approach would, however, be the same, as the identified relationships between needs, capabilities and more are not casestudy-specific. There are also more approaches and initiatives for analysing SoS s that may be used to approach the aim and research questions of this thesis that have not been investigated so far. The presented method in this thesis does, however, provide some insight into how product development can be approached from an $\mathrm{SoS}$ perspective, and how the corresponding research questions can be answered. 


\section{5 \\ Conclusions}

This thesis has shown how product development can be approached from a System-of-Systems (SoS) perspective. The theoretical background studies have been used to gather and synthesise knowledge from literature and similar initiatives. This has subsequently been used to propose a method with corresponding approaches that have been tested in the Search and Rescue (SAR) case studies of the appended papers. Overall, ontology and architecture frameworks have been the main approaches with which to approach the problem, aim and research questions outlined in the introduction chapter. The results from the performed case studies in the appended papers have shown that the holistic SoS design process from [1] can be partly covered using the architecture framework and ontology approaches as illustrated in Figure 3.1. Consequently, this thesis contributes to the realization of the holistic $\operatorname{SoS}$ design process.

Based on the results from the appended papers and the highlighted approaches in this thesis, the research questions can be answered as follows:

- RQ1: How can the needs of a system-of-systems be broken down into required capabilities and subsequently functions to be performed by constituent systems in a standardized and consistent way?

This thesis and the case study in paper III have shown that an architecture framework, namely the Unified Architecture Framework (UAF) can be used to provide a structured, standardized and consistent way of understanding the relationships that connect $\mathrm{SoS}$ needs to capabilities, activities, functions and means. Consequently, these governing relationships can be used to perform a breakdown of identified SoS needs. The functions and outcome of the architecture framework approach can subsequently be further processed, allocated to suitable means or Constituent Systems (CS), or used as inputs for a continued design process. 
- RQ2: How can a design space for system-of-systems be represented in a flexible manner that allows explorations?

Ontologies and description logic reasoning can be used to represent an SoS design space. An ontology representation allows for the incorporation of more knowledge at any time from different stakeholder perspectives, which results in a flexible, interoperable and scalable knowledge representation. This thesis and the case studies of papers [I], [II] and III] have shown that an ontology with reasoning capabilities can create an SoS design space through the suggested ontology approach and related process. SoS scenarios with involved entities and their relationships are used to model the ontology and design space representation. Initial design space explorations can then be performed by investigating how the design space reacts by changing ontology class definitions, for example.

- RQ3: In what way can a design space for system-of-systems be reduced and explored in an efficient and traceable way?

Like the answer to RQ2, ontology and description logic reasoning can be used to generate, reduce and also expand a design space representation, as shown in this thesis and in papers [I], [II] and [II]. Defined ontology classes containing necessary and sufficient conditions are used for the design space reduction purpose and the reasoner can populate these classes with the solutions that are able to fulfil the described conditions. The ontology approach is consequently used to filter the design space and generate a reduced representation of either alternatives or functions to be performed in a continued design process. The overall design space is kept after the reasoner has been invoked and the processing of the design space can be adjusted to widen or narrow down the scope of the reduced design space if desired. This adds to the traceability and efficiency of design space reductions and explorations with the proposed approach. 


\section{6 \\ Outlook and Future Work}

The performed work has contributed to the realization of a holistic SoS design process. However, additional work is needed to cover more aspects of every level in Figure 3.1. A prominent future endeavour is to perform design and trade space explorations on the obtained results from the proposed method of this thesis. As mentioned in chapter 4 , ontology can be used to perform initial design space explorations and indicate persistent solutions. However, additional investigations and methods are needed to perform more extensive explorations of design and trade spaces. The transition into matrix-based approaches from an ontology description would allow for more numerical calculation and optimization capabilities, but also for other means of visualizing a design space.

A Function/Means tree (F/M tree) is a promising procedure for a continued functional decomposition of derived functions. An F/M tree could thereby be used to approach both the Constituent Systems (CS) and sub-system design space levels in Figure 3.1. This, in combination with matrices for concept generation such as a matrix of alternatives or an Interactive Reconfigurable Matrix of Alternatives (IRMA), is an important next step for creating new system concepts with the proposed approaches.

The verification and validation of inferred ontology relationships in large domain representations is another important topic identified as future work. This is also a necessity for being able to reliably utilize a future meta-ontology structure. Consequently, meta-ontology structures and dynamic activation of relevant domain ontologies, and parts of a design space, are final topics relevant for future work. 


\section{7 \\ Review of Papers}

\section{Paper I}

\section{An Ontological Approach to System-of-Systems Engineering in Product Development}

This paper shows how an ontology with description logic reasoning capabilities can be used to generate and reduce a design space representation for Systemof-Systems (SoS), The paper also introduces a first version of the ontology development process seen in this thesis and illustrates how it can be used to create an ontology based on SoS scenarios. The proposed approach and process are then tested in a case study based on the Search and Rescue (SAR) operations of the Swedish Maritime Administration (SMA), The results from the case study show how a reasoner can assist in design space processing for SoSs and give suggestions on suitable solutions based on user defined queries. The work performed in this paper has acted as a foundation for papers [II] and III].

\section{Paper II}

\section{A System of Systems Approach for Search and Rescue Missions}

Based on the work presented in paper $[\mathrm{I}]$, this paper shows how the results from the ontology approach can be extracted and used to perform Agent-Based Simulations (ABS) to investigate different SoS constellations of SAR assets. Consequently, this paper shows how an approach with ontology and ABS can be used to generate, reduce and evaluate an SoS design space. Additionally, the performed case study shows how the ontology from paper [I] can be used as an existing domain ontology and how it subsequently can be expanded with more information using the ontology development process. 


\section{Paper III}

\section{A Breakdown of System of Systems Needs Using Architecture Frameworks, Ontologies and Description Logic Reasoning}

This paper presents an approach for breaking down $\mathrm{SoS}$ needs to required capabilities and their corresponding functions. The breakdown approach, also referred to as the architecture framework approach in this thesis, has been derived from the Unified Architecture Framework (UAF) Different UAF viewpoints have been used to provide a standardized and consistent way of understanding the relationships that exist between needs, capabilities, activities, functions, means and the environment. In this paper, a SAR case study is used to perform a breakdown of four basic needs with the proposed approach. The breakdown results in an initial design space of functions to be performed to fulfil the overarching capabilities and needs. Additionally, this paper shows how the outcome of the breakdown can be used as inputs for the ontology development process from paper [I] to allow for additional expressiveness. The outcome consequently corresponds to the domain of the ontology to be modelled. In a similar way to the case study in paper [II], the ontology model representing the breakdown is subsequently expanded with additional information, such as available SAR assets. Design space reductions are then performed using user defined queries and the reasoner, as done in papers [I] and [II. This finally results in a reduced design space of alternatives or functions to be performed to meet the overarching needs of an SoS. 


\section{Bibliography}

[1] I. Staack, K. Amadori, and C. Jouannet. "A holistic engineering approach to aeronautical product development". In: The Aeronautical Journal 123.1268 (2019), pp. 1545-1560. DOI: 10.1017/aer.2019.51.

[2] INCOSE. What is Systems Engineering? [Online]. Available from: https: //www.incose.org/about-systems-engineering. [Accessed 9 March 2021].

[3] INCOSE. Systems Engineering HandBook: A Guide for System Life Cycle Processes and Activities. 4th. San Diego, CA: International Council on Systems Engineering (INCOSE), 2015.

[4] M. W. Maier. "Architecting principles for systems-of-systems". In: Systems Engineering: The Journal of the International Council on Systems Engineering 1.4 (1998), pp. 267-284.

[5] A. Kossiakoff, W. N. Sweet, S. J. Seymour, and S. M. Biemer. Systems Engineering Principles and Practice. 2nd. Hoboken, New Jersey: John Wiley \& Sons, 2011.

[6] M. Jamshidi. System of Systems Engineering Principles and Applications. 1st. Boca Raton: CRC Press, Taylor \& Francis Group, 2009.

[7] R. Nola and H. Sankey. "The Hypothetico-Deductive Method". In: Theories of Scientific Method: An introduction. London. UK: Acumen, 2007. Chapter 7.

[8] N. Leveson. "The Drawbacks in Using The Term 'System of Systems"'. In: Biomedical Instrumentation \& Technology, AAMI 0.0 (2013), pp. $115-118$.

[9] J. Boardman and B. Sauser. "System of Systems - the meaning of of". In: Proceedings of the 2006 IEEE/SMC International Conference on System of Systems Engineering. Vol. 1. Los Angeles, CA: IEEE, 2006, pp. $118-123$.

[10] INCOSE. "INCOSE Systems of Systems Primer". In: INCOSE-TP2018-003-01.0 (2018). 
[11] J. S. Dahmann and K. J. Baldwin. "Understanding the Current State of US Defense Systems of Systems and the Implications for Systems Engineering". In: Proceedings of SysCon 2008 - IEEE International Systems Conference. Montreal, Canada: IEEE, 2008.

[12] J. A. Lane. "What is a System of Systems and Why Should I Care?" In: USC-CSSE-2013-001. University of Southern California, 2013. ISBN: 978-3-642-11828-9.

[13] C. Keating et al. "System of systems engineering". In: EMJ - Engineering Management Journal 15.3 (2003), pp. 36-45. ISSN: 10429247. DOI: 10.1080/10429247.2003.11415214.

[14] Office of the Deputy Under Secretary of Defence for Acquisition and Technology, Systems and Software Engineering. Systems Engineering Guide for System of Systems. Version 1.0. Washington, DC: ODUSD(AET)SSE, 2008.

[15] A. Gorod, B. Sauser, and J. Boardman. "System-of-Systems Engineering Management: A Review of Modern History and a Path Forward". In: IEEE Systems Journal 2.4 (2008), pp. 484-499. DOI: 10.1109/JSYST. 2008.2007163 .

[16] CAE. Capability Engineering, 2019. [Online]. Available from: https: // www . cae.com / media / documents / Defence_Security / Services_Documents/datasheet.capability.engineering.pdf. [Accessed 18 March 2021].

[17] J. A. Lane. "System of systems capability to requirements engineering". In: Proceedings of the 9th International Conference on System of Systems Engineering: The Socio-Technical Perspective, SoSE 2014 (2014), pp. 91-96. DOI: 10.1109/SYSOSE.2014.6892469

[18] J. Dahmann, J. A. Lane, G. Rebovich, and R. Lowry. "Systems of systems test and evaluation challenges". In: 2010 5th International Conference on System of Systems Engineering. 2010, pp. 1-6. DOI: 10.1109/ SYSOSE.2010.5543979.

[19] J. A. Lane and T. Bohn. Using SysML to Evolve Systems of Systems. Tech. rep. INCOSE, 2010.

[20] R. Williamson. INCOSE (MBSE) Model Based System Engineering (SoS) System of Systems/Enterprise Activity Introduction. 2012.

[21] M. Mori et al. "Systems-of-systems modeling using a comprehensive viewpoint-based SysML profile". In: Journal of Software: Evolution and Process 30.3 (2018), pp. 1-20. ISSN: 20477481. DOI: 10.1002/smr.1878.

[22] Z. Li, C. Sim, and M. Y. H. Low. "A Survey of Emergent Behavior and Its Impacts in Agent-based Systems". In: Proceedings of the IEEE International Conference on Industrial Informatics. Sept. 2006, pp. 12951300. DOI: 10.1109/INDIN.2006.275846 
[23] MITRE. Systems Engineering Guide - Collected wisdom from MITRE's systems engineering experts. The MITRE Corporation, 2014. ISBN: 9780-615-97442-2.

[24] Object Management Group (OMG). Unified Architecture Framework. [Online]. Available from: https://www.omg.org/uaf/index.htm. [Accessed 24 March 2021].

[25] Object Management Group (OMG). About the Unified Architecture Framework Specification Version 1.1. [Online]. Available from: https: //www.omg.org/spec/UAF/About-UAF/. [Accessed 24 March 2021].

[26] Object Management Group (OMG). Unified Architecture Framework (UAF) Domain Metamodel, Version 1.1. 2020.

[27] Object Management Group (OMG). Unified Architecture Framework (UAF) Sample Problem (Informative). Tech. rep. OMG Unified Architecture Framework, 2018.

[28] J. Bankauskaite and A. Morkevicius. "Towards an Automated UAFbased Trade Study Process for System of Systems Architecture". In: 30th Annual INCOSE International Symposium, Virtual Event. July 2020.

[29] D. H. Meadows. Thinking in Systems: A Primer. 1st. Chelsea: Chelsea Green Publishing, 2008.

[30] L. B. Rainey and A. Tolk. Modeling and Simulation Support for System of Systems Engineering Applications. 1st. New Jersey: Wiley, 2015.

[31] N. F. Noy and D. L. McGuinnes. Ontology Development 101: A Guide to Creating Your first ontology. Stanford University, 2000.

[32] T. R. Gruber. "A translation approach to portable ontology specifications". In: Knowledge Acquisition 5.2 (1993), pp. 199-220.

[33] D. Allemang and J. Hendler. Semantic Web for the Working Ontologist Effective Modeling in RDFS and OWL. 2nd. Waltham, Boston: Elsevier, 2011.

[34] D. Kalibatiene and O. Vasilecas. "Survey on Ontology Languages". In: Lecture Notes in Business Information Processing, 2011. ISBN: 978-3642-33280-7. DOI: 10.1007/978-3-642-33281-4.

[35] M. Horridge et al. A Practical Guide To Building OWL Ontologies Using Protégè 4 and CO-ODE Tools Edition 1.3. Tech. rep. The University of Manchester, 2011.

[36] S. Abburu. "A Survey on Ontology Reasoners and Comparison". In: International Journal of Computer Applications 57.17 (2012), pp. 3339. DOI: 10.5120/9208-3748.

[37] T. Lampoltshammer and S. Wiegand. "Improving the Computational Performance of Ontology-Based Classification Using Graph Databases". In: Remote Sensing 7 (July 2015), pp. 9473-9491. DOI: $10.3390 /$ rs70709473 
[38] V. Haarslev and R. Möller. "On the Scalability of Description Logic Instance Retrieval". In: Journal of Automated Reasoning 41 (Aug. 2008), pp. 99-142. DOI: $10.1007 / \mathrm{s} 10817-008-9104-7$.

[39] K. Stock, D. G. Leibovici, L. Delazari, and R. Santos. "Discovering Order in Chaos: Using a Heuristic Ontology to Derive Spatio-Temporal Sequences for Cadastral Data". In: Spatial Cognition $\&$ Computation 15 (2015), pp. 115-141.

[40] B. Smith. Basic Formal Ontology 2.0 Specification and User's Guide. 2015 .

[41] V. Mascardi, V. Cordì, and P. Rosso. "A Comparison of Upper Ontologies." In: 8th AI*IA/TABOO Joint Workshop "From Objects to Agents": Agents and Industry: Technological Applications of Software Agents. 2007, pp. 55-64.

[42] M. Ast, M. Glas, and T. Roehm. "Creating an ontology for aircraft design, an experience report about development process and the resulting ontology". In: Deutscher Luft-und Raumfahrtkongress. 2013.

[43] P. Morosoff et al. "Joint doctrine ontology: A benchmark for military information systems interoperability". In: CEUR Workshop Proceedings. Vol. 1523. 2015, pp. 2-9.

[44] H. Dogan, M. J. Henshaw, and J. Johnson. "An incremental hybridisation of heterogeneous case studies to develop an ontology for capability engineering". In: INCOSE International Symposium. Vol. 22. Rome: INCOSE, 2012, pp. 956-971.

[45] J. S. Osmundson, T. V. Huynh, and P. Shaw. "Developing Ontologies for Interoperability of Systems of Systems". In: Conference on Systems Engineering Research. 2006.

[46] L. C. Van Ruijven. "Ontology for systems engineering". In: Conference on Systems Engineering Research, CSER'13. Procedia Computer Science 16, 2012, pp. 383-392.

[47] C. Hennig, A. Viehl, B. Kämpgen, and H. Eisenmann. "Ontology-Based Design of Space Systems". In: International Semantic Web Conference. ISWC, 2016, pp. 308-324.

[48] G. Langford and T. Langford. "The making of a system of systems: Ontology reveals the true nature of emergence". In: 12th System of Systems Engineering Conference (SoSE). IEEE, 2017, pp. 1-5.

[49] D. A. Wagner et al. "An Ontology for State Analysis: Formalizing the Mapping to SysML". In: 2012 IEEE Aerospace Conference. IEEE, 2012, pp. $1-16$. 
[50] S. Jenkins. Introduction to System Modeling and Ontologies. [PowerPoint presentation]. Available from: https://trs.jpl.nasa.gov/bitstream/ handle/2014/42081/11-1269.pdf?sequence=1. 2011, [Accessed 29 April 2021].

[51] H. Wardhana, A. Ashari, and A. K. Sari. "Transformation of SysML Requirement Diagram into OWL Ontologies". In: International Journal of Advanced Computer Science and Applications (IJACSA) 11.4 (2020), pp. 106-114. DOI: 10.14569/IJACSA.2020.0110415

[52] L. Yang, K. Cormican, and M. Yu. "Ontology-based systems engineering: A state-of-the-art review". In: Computers in Industry 111 (2019), pp. 148-171. DOI: https://doi.org/10.1016/j.compind.2019.05.003

[53] C. E. Dickerson and D. N. Mavris. Architecture and Principles of Systems Engineering. 1st ed. Boca Raton: CRC Press, 2010.

[54] P. Krus. "An Information Theoretical Perspective on Design". In: Proceedings of the International Conference on Engieerig Design (ICED'07). Paris, France: ICED'07, 2007.

[55] M. Rosinger, M. Buker, and R. Weber. "An Approach to Guide the System Engineer during the Design Space Exploration Process". In: Proceedings of CEUR Workshop - Software Engineering Workshops (SEWS). Mar. 2015, pp. 81-90.

[56] E. Kang, E. Jackson, and W. Schulte. "An Approach for Effective Design Space Exploration". In: Calinescu R., Jackson E. (eds) Foundations of Computer Software. Modeling, Development, and Verification of Adaptive Systems. Monterey Workshop 2010. Lecture Notes in Computer Science. Vol. 6662. Springer, Berlin, Heidelberg, 2011. DoI: 10.1007/978-3642-21292-5_3.

[57] P. Krus. "Information Entropy in the Design Process". In: Proceedings of the International Conference on Research into Design (ICoRD'13. Chennai, India: ICoRD'13, 2013.

[58] National Aeronautics and Space Administration (NASA). NASA Systems Engineering Handbook. Military Bookshop, 2016. ISBN: 9781680920895.

[59] A. Ross and D. Hastings. "The Tradespace Exploration Paradigm". In: INCOSE International Symposium 15 (July 2005). DOI: 10.1002/j.23345837.2005.tb00783.x.

[60] Scaled Agile, Inc. Set-Based Design. [Online]. Available from: https: / / www . scaledagileframework . com/set - based-design/. [Accessed 26 April 2021].

[61] A. J. Robotham. "The Use of Function/Means Trees for Modelling Technical, Semantic and Business Functions". In: Journal of Engineering Design (2002), pp. 243-251. DOI: 10.1080/09544820110108944. 
[62] B. O'sullivan. "Interactive constraint-aided conceptual design". In: Artificial Intelligence for Engineering Design, Analysis and Manufacturing 16.4 (2002), pp. 303-328. DOI: 10.1017/S0890060402164043.

[63] S. D. Eppinger and T. R. Browning. Design Structure Matrix Methods and Applications. Cambridge: MIT Press, 2012. ISBN: 9780262301428.

[64] T. Ritchey. "Fritz Zwicky, Morphologie and Policy Analysis". In: 16th EURO conference on Operational Analysis. Brussels, 1998.

[65] M. Schmit et al. "Semantic design space refinement for model-based systems engineering". In: 10th Annual International Systems Conference, SysCon 2016 - Proceedings. 2016. ISBN: 9781467395182. DOI: 10.1109/ SYSCON.2016.7490579

[66] K. Lynch et al. "Conceptual design acceleration for cyber-physical systems". In: Annual IEEE International Systems Conference (SysCon). Apr. 2017, pp. 1-6.

[67] M. Jändel et al. Visual Analytics - Perspectives on the Field of Interactive Visualization. Swedish Defence Research Agency (FOI), 2016. ISBN: 1650-1942.

[68] ICAO/IMO. IAMSAR Manual - International Aeronautical and Maritime Search and Rescue Manual - Volume 1 Organization and Management. 10th. Montréal, Quebec: International Civil Aviation Organization and International Maritime Organization, 2016. ISBN: 978-92-9258-0575 .

[69] ICAO/IMO. IAMSAR Manual - International Aeronautical and Maritime Search and Rescue Manual - Volume 2 Mission Co-ordination. 7th. Montréal, Quebec: International Civil Aviation Organization and International Maritime Organization, 2016. ISBN: 978-92-9258-058-2.

[70] ICAO/IMO. IAMSAR Manual - International Aeronautical and Maritime Search and Rescue Manual - Volume 3 Mobile Facilities. 10th. Montréal, Quebec: International Civil Aviation Organization and International Maritime Organization, 2016. ISBN: 978-92-9258-059-9.

[71] Sjöfartsverket. Sjö- och flygräddning. [Online]. Available from: https: //www.sjofartsverket.se/Sjofart/Sjo--och-flygraddning/. [Accessed 29 March 2021].

[72] M. Halléhn. Svenskt Program för Sjö- och Flygräddning. In Sjöfartsverket Document Nr: RADDALIV-6-182 (in swedish). 2019.

[73] No Magic, Inc. UAF Plugin 19.0 LTR Documentation. [Online]. Available from: https: / / docs . nomagic . com / display / UAFP190 / UAF + elements. [Accessed 30 March 2021]. 
[74] M. A. Musen. "The Protégé project. A look back and a look forward". In: AI Matters. Association of Computing Machinery Specific Interest Group in Artificial Intelligence 1.4 (2015). DOI: 10.1145/2557001. 25757003

[75] R. Arp, B. Smith, and A. D. Spear. Building Ontologies with Basic Formal Ontology. The MIT Press, 2015. ISBN: 0262527812, 9780262527811.

[76] R. Stevens, M. Stevens, N. Matentzoglu, and S. Jupp. Manchester Family History Advanced OWL Tutorial. Tech. rep. Manchester: The University of Manchester, 2015.

[77] K. Schekotihin, P. Rodler, and W. Schmid. OntoDebug: Interactive Ontology Debugging Plug-in for Protégé. Tech. rep. Klagenfurt: AlpenAdria-Universität, 2018. DOI: $10.1007 / 978-3-642-11829-6$. 


\section{Papers}

The papers associated with this thesis have been removed for copyright reasons. For more details about these see:

http://urn.kb.se/resolve?urn=urn:nbn:se:liu:diva-175766 
There's always a bigger fish

Qui-Gon Jinn 


\section{FACULTY OF SCIENCE AND ENGINEERING}

Linköping Studies in Science and Technology, Licentiate Thesis No. 1907, 2021 Department of Management and Engineering

Linköping University

SE-581 83 Linköping, Sweden

www.liu.se
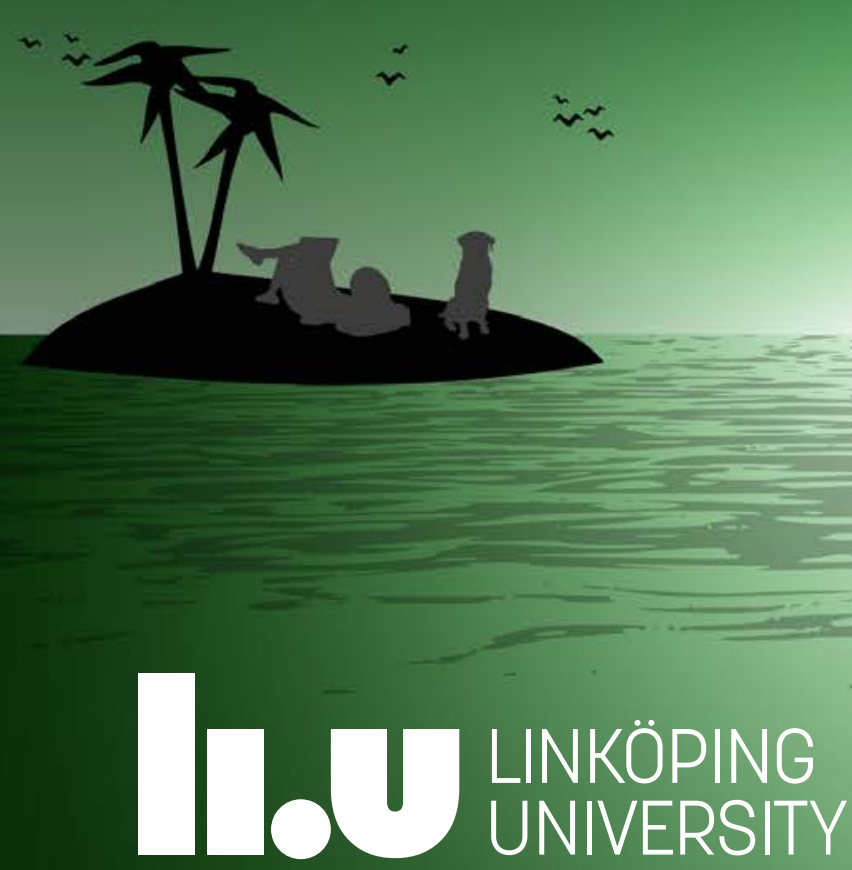